2

\title{
Ice storm damage to trees in mixed Central European forests: damage patterns, predictors and susceptibility of tree species
}

\author{
Matija Klopčič ${ }^{1 *}$, Aleš Poljanec ${ }^{2}$, Mojca Dolinar ${ }^{3}$, Damijana Kastelec $^{4}$ and Andrej \\ Bončina $^{1}$ \\ ${ }^{1}$ University of Ljubljana, Biotechnical Faculty, Department of Forestry and Renewable Forest \\ Resource, Večna pot 83, 1000 Ljubljana, Slovenia \\ ${ }^{2}$ Slovenia Forest Service, Večna pot 2, 1000 Ljubljana, Slovenia \\ ${ }^{3}$ Slovenian Environmental Agency, Vojkova 1b, 1000 Ljubljana, Slovenia
}

${ }^{4}$ University of Ljubljana, Biotechnical Faculty, Department of Agronomy, Jamnikarjeva 101, 1000

Ljubljana, Slovenia

*Corresponding author: Tel: +386 132035 51; Fax: +386 125711 69; Email: matija.klopcic@bf.uni-lj.si

\section{Abstract}

In northern temperate forests, ice storms are a common disturbance agent, though climate change may alter their occurrence patterns. Their impact on forest ecosystems is complex, as they influence both structure and processes. In 2014 an ice storm of high intensity and large spatial extent occurred in Slovenia, Central Europe, which enabled a detailed study of ice damage to individual trees across a broader spatial scale. Pre- and post-ice storm measurement data on 11,414 trees on 960 permanent plots were used to examine ice damage patterns on trees in the disturbed forest area $\left(\approx 8,700 \mathrm{~km}^{2}\right)$ to determine the predictors of ice damage to trees and to investigate the relative susceptibility of eight groups of tree species in mixed Central European forests. We used a novel approach to modelling ice storm intensity across the region based on measured data on air temperature, precipitation amount and duration, precipitation intensity and wind speed. The ice storm damaged 
$2731 \%$ of the analysed trees; high variability in the damage rate was observed across the disturbed area. For the tree species, a susceptibility to ice damage index (SI) ranging between 0 (no damage) and 1 (complete damage) was calculated based on terrestrial assessment of trees. Tree species differed significantly in susceptibility to ice damage: Abies alba $(\mathrm{SI}=0.14)$ and Quercus sp. $(\mathrm{SI}=0.11)$ were rather resistant; Picea abies, Fagus sylvatica and Acer sp. $(\mathrm{SI}=0.23-0.28)$ were moderately to very susceptible; and Pinus sp. ( $\mathrm{Sl}=0.62)$ was extremely susceptible to ice damage. Eight predictors and three interactions were included in an ordinal logistic regression model of tree damage: ice damage on trees depends mainly on ice storm intensity, elevation, and tree species, while tree dbh and social status, tree size and tree species diversity indices, and slope were relatively less important. Our study illustrates the complexity of damage patterns on trees due to ice storms and the significance of ice storm intensity and tree species as predictors when modelling ice damage on individual trees.

\section{Keywords}

41 natural disturbance; ice storm damage; ice storm intensity; susceptibility index; ordinal

42 logistic regression; Slovenia 


\section{Introduction}

Disturbance significantly influences the dynamics of natural and managed forests across the globe. Among disturbance agents, fire, insects, snow and wind have been thoroughly studied, but less is known about ice accumulation. An ice storm can be separated into two unique components: 1) the meteorological event that produces glaze and 2) the response of the biota to ice accumulation (Bragg et al., 2003). The first occurs when a moist air mass of above-zero temperature lies above a colder surface layer of subzero temperature air. Droplets falling from the upper air layer become supercooled as they pass through the layer of cold air and freeze upon contact with objects on the surface (Carrière et al., 2000). There is no generally accepted definition of an ice storm; the National Weather Service in the USA defines an ice storm as an occurrence of freezing precipitation, resulting in either structural damage or at least $6.35 \mathrm{~mm}$ of ice accumulation on exposed surfaces (Irland, 2000). Ice storms can cause massive damage to human infrastructure, as well as to agricultural crops and forests (Zhou et al., 2011).

In forests of the northern temperate zone, ice storms are a common natural disturbance agent, but their intensity and frequency differ within and between continents. They are relatively more frequent in the temperate zone of North America (e.g. Oliver and Larson, 1996; Frelich, 2002), but less so in East Asia (Zhou et al., 2011) and Europe (Kämäräinen et al., 2017). In European forests, ice storms are a common disturbance agent, but far less important than fire, insects, snow or wind (Schelhaas et al., 2003). In some parts of Europe (e.g. the Dinaric Mountains, some areas of the Alps), however, ice storms are frequent and may periodically cause extensive damage (Carrière et al., 2000; Nagel et al., 2017). Ice storms can be local or regional, even affecting millions of hectares in a single event. Usually they cause minor damage, but periodically they can result in a catastrophe. The return interval of ice storms varies greatly with location and can range from a few months to several years, decades, or even centuries for catastrophic ice storms. In Europe, freezing rain typically appears between November and February (Carrière et al., 2000) and is more frequent in 
events annually) (Kämäräinen et al., 2017). In many parts of Europe, ice storms appear to be much more frequent than reported by observers (Bernstein et al., 2009), since they are mostly of low intensity and cause no or minor damage. Climate change may alter the frequency and intensity of ice storms; both increasing (Klima and Morgan, 2015) and decreasing (Seidl et al., 2017) frequency and intensity of ice storms have been forecasted.

When an ice storm occurs, several components of forest ecosystems, as well as many processes of forest dynamics, may be significantly affected (Oliver and Larson, 1996; Ge et al., 2015); for example,

forest stands and individual live trees suffer damage, woody debris loads increase due to tree injuries and higher mortality of trees, and wildlife may experience mortality and habitat modification. Ice accumulation can cause tree damage ranging from the loss of tissue to fatal injury (Lemon, 1961). The most frequent tree injuries are minor to major twig and branch breakage and subsequent crown loss, crown bending on a temporary or permanent basis, trunk breakage or split within or below the crown, and root system damage with possible uprooting (Miller-Weeks et al., 1999).

Tree damage results from the complex interactions among disturbance intensity, biological factors related to the tree and stand attributes, physical site conditions and other external aggravating factors (e.g. Jones et al., 2001; Kenderes et al., 2007). In general, disturbance intensity is the physical measure of a disturbance over a given area (Frelich, 2002); in the case of an ice storm, this measure can be the ice load thickness on trees. However, due to the lack of reliable data, the measured ice load thickness has rarely been examined as an explanatory variable for tree damage (e.g. Proulx and Greene, 2001). It is possible to measure ice thickness in ice storm manipulation experiments, but such measurements are rare (e.g. Rustad and Campbell, 2012; Nock et al., 2016). Thus, most studies have included proxies for ice storm intensity that are for the most part assessed indirectly from damage on studied plots (e.g. Nagel et al., 2016). However, when an indicator of ice storm intensity 
occurrence or even the type of tree damage, including broken twigs, branches or tree-tops or snapping, bending or uprooting of a tree (Proulx and Greene, 2001; Aubrey et al., 2007).

The biomechanics of trees may play a major role in damage occurrence and type (Bragg et al., 2003). Tree species and tree size should capture most of the relevant traits contributing to tree damage due to ice loads (Bragg et al., 2003). In studies from North America, tree susceptibility to ice damage as well as inflicted tree injuries have often been considered to be species-specific (e.g. Bruderle and Stearns, 1985; Rebertus et al., 1997; Hopkin et al., 2003; Priebe et al., 2018), but the genotype within species can also be relevant. For instance, narrow crown genotypes may experience less ice storminduced damage than broader crown genotypes of the same species (Pile et al., 2016). The literature, however, offers only minimal agreement on species' susceptibility to ice load injuries (e.g. Boerner et al., 1988).

In addition, the silvicultural treatment of a stand prior to an ice storm may also influence ice damage on trees. The exact effect of treatment is difficult to determine due to many interrelated variables (Bragg et al., 2003). In general, managed stands should not be more prone to ice damage than unmanaged stands (e.g. Nielsen et al., 2003); however, the intensity of thinning has been recognized as a factor negatively influencing the resistance of stands and trees in the short run (Zarnovican, 2001).

Additionally, the interaction of ice with other disturbance agents, especially wind and snow, may cause increased susceptibility of stands and trees to ice damage (Coder, 2015), but relations among disturbance drivers may be modified by climate change (Seidl et al., 2017).

Studies on the impact of ice storms on European forests are rather rare relative to studies on other disturbance agents. There are two main reasons for this: 1) ice storms are usually low-severity, localscale events, and 2) massive ice storms are rare relative to windthrow, fire or breakage due to snow load. Consequently, relatively little is known about the susceptibility of tree species to ice damage in Europe. In addition, no model has been developed so far to show the mutual influences of ice storm intensity, tree and stand attributes, and site characteristics on ice damage to trees. 
In 2014 an ice storm of the largest intensity and spatial extent ever recorded occurred in Slovenia

122

123

124

125

126

127

128

129

130 and Croatia (Nagel et al., 2017), causing extensive damage to more than half of Slovenian forests. This represented an opportunity to study ice damage patterns for trees in various forest stands across a broad range of site conditions and at different ice storm intensities. Studies of this event assessed the general damage rate in forests (Šimić Milas et al., 2015) or were limited to some localities of unmanaged forests (Nagel et al., 2016) or to a single tree species and consecutive disturbances (de Groot et al., 2018). However, a detailed study of ice damage to individual trees across a broader range of forests together with an evaluation of tree species susceptibility to ice damage on a regional spatial scale is missing. The aims of our study were thus to 1 ) examine ice damage patterns on individual trees in relation to different ice storm intensities in managed mixed forests at the regional scale, 2) determine the predictors of ice damage occurrence and severity with the main focus on tree and stand attributes, and 3) quantify and examine the relative susceptibility of tree species to ice damage.

\section{Methods}

\subsection{Study area}

The forests of Slovenia, which cover approximately $11,800 \mathrm{~km}^{2}$, were used as the study area (Figure 1). The area is characterised by considerable variation in relief and climatic conditions. The mean annual temperature is $7.8^{\circ} \mathrm{C}$, and ranges from $-2^{\circ} \mathrm{C}$ in the Alps to $14^{\circ} \mathrm{C}$ in the coastal region, while the total mean annual precipitation is $1734 \mathrm{~mm}$, and ranges from $800 \mathrm{~mm}$ in the eastern part to almost $4000 \mathrm{~mm}$ in the northwestern part of Slovenia. Elevation ranges from 0 to $2864 \mathrm{~m}$, with the majority of forest lying in the belt between 400 and $1200 \mathrm{~m}$. Approximately half of forests grow on limestone and dolomite, and the another half grow on silicate or mixed parent material on which both cambisols and leptosols of different depths evolved. 
Forests cover $60 \%$ of the area. The main tree species are Fagus sylvatica (European beech; $32 \%$ of total growing stock), Picea abies (Norway spruce; $31 \%$ ), Abies alba (silver fir; $7 \%$ ), Quercus species (7\%), Pinus species (6\%) and Acer species (5\%). In addition, a number of minor tree species are admixed in these forests (see Table A1 in the Appendix). The forests are characterised by small-scale natural regeneration-based forest management, with the irregular shelterwood system being the prevailing silvicultural system. This system creates a horizontal mosaic of stands of different ages (i.e. developmental phases). The mean stand basal area nationwide amounts to around $30 \mathrm{~m}^{2} \mathrm{ha}^{-1}$ (Slovenia Forest Service, 2014).

Between January 29 and February 5, 2014, an extensive ice storm affected a large part of Slovenia. Over this period, much of the affected area received more than $90 \mathrm{~mm}$ of precipitation. A sizable area received more than 150-200 mm (Vertačnik et al., 2015), and the highest registered amount of precipitation reached $300-400 \mathrm{~mm}$ (ARSO, 2014a). Due to high air temperatures in the upper atmospheric layers and a subzero air mass near the surface, the falling rain converted to supercooled freezing rain which created $20-60 \mathrm{~mm}$, and at times even up to $90-100 \mathrm{~mm}$, of ice accumulation (Sinjur et al., 2014). There were no reports of significant winds during the studied disturbance event, indicating that wind did not meaningfully contribute to forest damage (ARSO, 2014a). Although the ice storm affected almost the entire area of Slovenia, its severity differed across the country (Figure 1). Approximately $8,700 \mathrm{~km}^{2}$ was impacted, and in total 5.76 million $\mathrm{m}^{3}$ of timber was harvested in 2014-2017 due to ice damage, with a large number of damaged trees left in the forests (Slovenia Forest Service, 2018).

\subsection{Data}

The study is based on individual tree data $(n=11,414)$ from 960 permanent sampling plots that were inventoried in the year before the ice storm and re-inventoried a few months after the ice storm 
forest area of the country, and repeats the inventory every ten years. The inventory is carried out in a systematic grid of permanent sampling plots of $200 \mathrm{~m}^{2}$, on which all trees $\geq 10 \mathrm{~cm}$ dbh are surveyed. Plots are located on a $250 \times 500 \mathrm{~m}$ grid with known longitude and latitude coordinates of each plot centre.

175
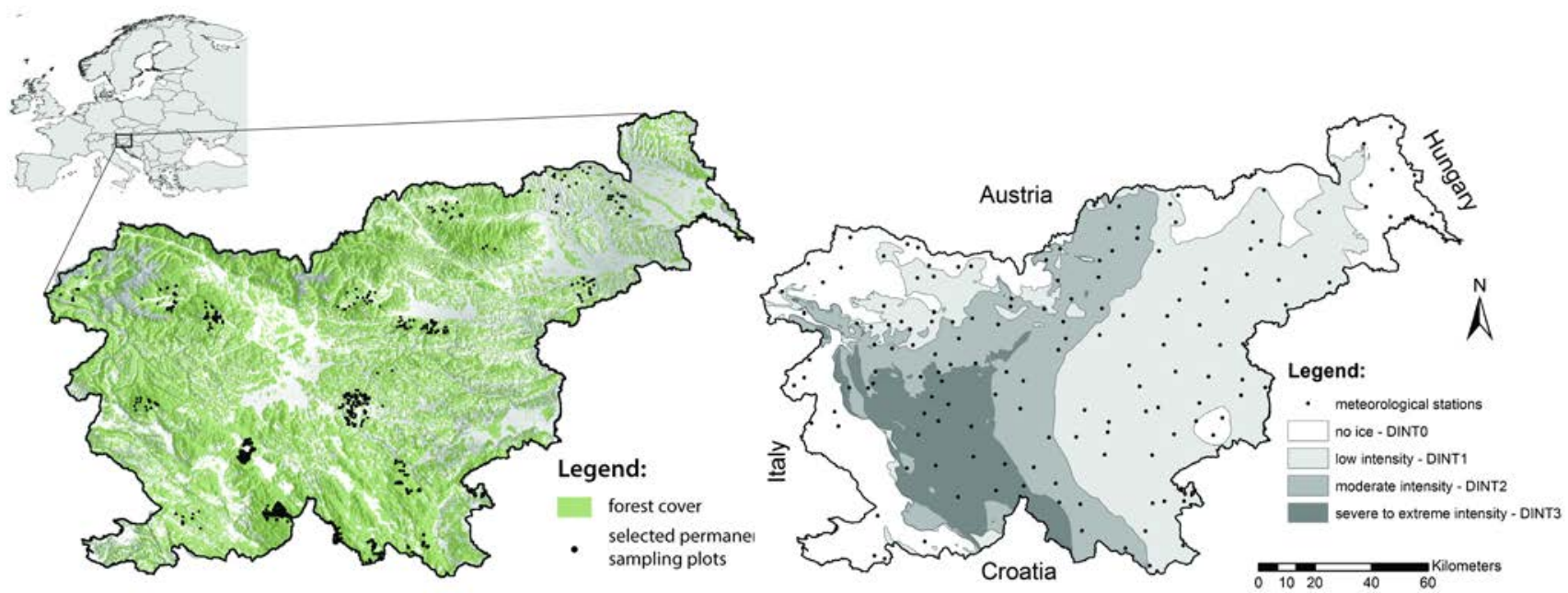

Figure 1: Forest cover in Slovenia with locations of selected permanent sampling plots (left) and the 2014 ice storm intensity (ARSO, 2014b) with locations of meteorological stations used in the study (right) variables and 4) topographic variables.

\subsubsection{Ice storm intensity}

Ice storm intensity (DINT) was assessed based on ice thickness, which was estimated based on the liquid rainfall amount during temperature conditions favourable for ice formation. Glaze ice occurrence is a meteorological variable that is systematically observed at the manned meteorological station network of the Slovenian Environment Agency. The main deficiency of ice observations is the lack of information on ice thickness. Therefore, we assessed ice thickness based 
on measured meteorological variables: 1) air temperature, 2) precipitation amount and duration, 3) precipitation intensity and 4) wind speed.

The area affected by ice was modelled using daily surface air temperature, the vertical temperature profile and precipitation measurements during the eight-day ice storm period. In the first step, maps of spatial distributions of surface temperature and precipitation amounts were produced (see also Figure SM1 in the Online Supplementary Material). From point measurements, both air temperature and precipitation values were interpolated into a regular $100 \mathrm{~m}$ grid using the residual kriging spatial interpolation methodology (Cressie, 1993). Previous studies (Dolinar, 2005, 2014; Tveito et al., 2008) have shown that, with the given measurement network density on the Slovenian territory, the best results in spatial interpolation are obtained with the residual kriging methodology using geographical variables (i.e. longitude, latitude, and elevation) and, in the case of precipitation, also radar measurements as explanatory variables. The same studies have shown that the highest spatial resolution in which the spatial variability of an interpolated climate variable could be explained by a given spatial network density is between 1000 and $100 \mathrm{~m}$. Based on automatic precipitation measurements ( 37 weather stations), the daily time period of precipitation was determined for each day of the ice storm. The spatial distribution of mean surface air temperature (measured at 153 stations; Figure 1) was calculated only for daily time periods in which liquid precipitation was observed and registered.

The vertical temperature profile is a key element for ice formation (Vertačnik et al., 2015); a distinct temperature inversion with a cold near-surface air mass and a layer of relatively warm air at higher altitudes must exist for ice load to occur. During the 2014 ice storm, the vertical temperature profile changed noticeably across the study area. It was calculated regionally based on in-situ temperature measurements at different elevations and radiosonde measurements over Udine (Italy), Ljubljana

213 (Slovenia), Graz (Austria) and Zagreb (Croatia) and was used as a vertical temperature gradient twice in the DINT modelling: firstly, in the surface air temperature spatial interpolation procedure as a part of the linear model describing the relationship between temperature and elevation, and secondly as 
a binary layer (i.e. ice formation possible or not possible) to determine the potential area for ice formation (see step 2 below). The spatial distribution of liquid precipitation was calculated based on hourly (measured at 37 stations) and daily (measured at 212 stations) precipitation measurements. The proportion of liquid precipitation was determined based on the hourly temperature course and on daily observations of precipitation type. As explained above, the spatial distribution of the amount of liquid precipitation was calculated on a 100-m regular grid using residual kriging (Cressie, 1993). In the second step, the potential area of ice formation was determined as the territory where the mean temperature during the rainfall event was below the freezing point $\left(0^{\circ} \mathrm{C}\right)$, reduced by the area where the vertical temperature profile described above did not meet the criteria for ice formation. measurements, wind speed and mean air temperature. The next step was to produce the daily ice storm intensity maps. In these maps, only two ice storm intensity categories were determined (i.e. ice storm occurred or did not occur), and the threshold was between 10 and $20 \mathrm{~mm}$ of the daily precipitation amount. A shifting threshold of ice load occurrence was used due to high local variation in air temperature and wind velocity, which, together with rainfall intensity, primarily determine the collision efficiency of raindrops with cold objects and thus ice formation (Jones, 1996; Makkonen, 2000). Collision efficiency increases with higher wind velocity and rainfall intensity; thus, the threshold between two ice storm intensity categories is lower. The exact threshold was thus determined empirically, considering the

237 information on ice damage. Lastly, the final map of ice storm intensity for the whole ice storm event (hereafter the final map) combined individual daily ice storm intensity maps for the entire eight-day duration of the ice storm. The final map of the predicted ice storm intensity classified ice storm intensity (DINT) into four categories (Figure 1): 
- DINTO - no ice $(\leq 0.1 \mathrm{~mm})$,

- DINT1 - low intensity with thin ice accretion (>0.1-5 mm),

- DINT2 - moderate intensity with thick ice accretion (>5-20 mm),

- $\quad$ DINT3 - severe to extreme intensity with very thick ice accretion (>20 mm).

246 The ice thickness range for a single category was assessed empirically, based on the precipitation

247 sum during the entire eight-day event and on field reports on damage and ice thickness.

Finally, the field observation data on ice occurrence were used for validation of the model of the ice storm intensity. The map of the actual ice storm affected region (hereafter validation map) was determined by spatial interpolation of ice occurrence observations (presence/absence of ice observed at 212 stations) using the indicator kriging methodology (Cressie, 1993). This validation map was compared to the final map. Only two categories could be compared between both maps ice-affected and non-affected areas. The ice-affected area covered 15,098 $\mathrm{km}^{2}$ and the non-affected area covered 5,169 $\mathrm{km}^{2}$ on the final map. The two maps, namely the final map and the validation map, do not match only on an area of $319 \mathrm{~km}^{2}$ (1.6 \% of the entire country), exhibiting rather small spatial interpolation error.

\subsubsection{Tree variables}

260

On each sampling plot, individual tree data were recorded a few months before the ice storm. Fortytwo tree species were identified in the inventory (see Supplementary material, Table SM1). According to similarities in species characteristics, their dominance in stands (i.e. dominant species were treated separately, co-dominant (minor) species were grouped into larger groups), and frequency (i.e. $n>200$ ), species were classified into six groups of species (SPEC) to make the analysis feasible and transparent: 1) Abies alba (hereinafter Abies), 2) Picea abies (hereinafter Picea), 3) Pinus sylvestris (Scots pine) \& Pinus nigra (Austrian pine) (hereinafter Pinus), 4) Fagus sylvatica 

pseudoplatanus (sycamore maple) \& Acer platanoides (Norway maple) (hereinafter Acer). Other tree species were treated as two additional groups, namely other broadleaves and other conifers, and were included into some analyses, but not the modelling. This was because of the great heterogeneity in characteristics of tree species included in both groups, which might significantly influence the results and make their interpretation difficult. For each tree, dbh was measured with a calliper rounded to the last completed $\mathrm{cm}$. Social status (SS) was assessed for each tree based the relative height of the tree and its position within the vertical structure of the stand (Klopcic and Boncina, 2010) and classified into three categories: SS1 - predominant and dominant trees, SS2 - codominant and intermediate trees and SS3 - understorey suppressed trees.

The individual tree data gathered on 960 plots before the ice storm were supplemented by a fieldbased estimation of the ice storm damage of individual trees on the plots eight months after the ice storm. This survey was done by the Slovenia Forest Service (Poljanec, 2014) to estimate the amount of damaged wood and the proportion of trees able to survive the ice damage, which was important for decision making on sanitation of the damaged forest stands. Trees were classified into four categories based on a visual assessment of damage, hereafter referred to as tree damage class (TDAM) (adapted after Miller-Weeks et al., 1999):

D0) Trees with no visual damage.

D1) Trees with moderate damage: broadleaves with less than $50 \%$ crown damage and conifers with a broken top of less than $1 / 3$ of the crown length, moderately leaning trees $\left(<45^{\circ}\right)$.

D2) Trees with severe damage: broadleaves with 50-75 \% crown damage and conifers with broken tops between $1 / 3$ and $2 / 3$ of the crown length.

D3) Trees with total damage: broadleaves with $\geq 75 \%$ crown damage and conifers with a broken top of more than $2 / 3$ of the crown length, trees snapped below the crown, cleaved trees, severely leaning trees $\left(>45^{\circ}\right)$ and uprooted trees. 
At the plot level, data related to the site and stand conditions were compiled. Site variables (elevation, slope and topographic position) were derived from a digital elevation model (12.5 m resolution) (GURS, 2014). Stand conditions were represented by three variables: quadratic mean diameter (QMD) (Curtis and Marshall, 2000), the Gini index (Weiner and Solbrig, 1984) and the Shannon-Wiener index (SWI) (Spellerberg, 2008). The Gini index expresses the tree size diversity and is measured on a scale from 0 to 1 ; it is 0 if all trees on a plot are of equal size, while it has a theoretical maximum of 1 in an infinite population in which all trees but one have a size of 0 - the ultimate in inequality (Weiner and Solbrig, 1984). A higher Gini index indicates uneven-sized stands, while a value near 0 indicates an even-sized structure of forest stands. In our study, the Gini index was calculated using the number of trees and their basal area per plot and was calculated only for plots on which more than five trees were registered. For plots with less than 50 trees, the calculated Gini index was corrected by the quotient $n /(n-1)$ to reduce bias due to small sample size (Weiner and Solbrig, 1984). SWI was applied to assess tree species diversity; in order to be consistent with the variable SPEC, it was calculated based on the basal area proportions of the eight groups of tree species per plot, namely the six target species, other broadleaves, and other conifers.

\subsection{Data analyses}

For each analysed tree species, we calculated the susceptibility index SI using equation 1 (adapted after Rebertus et al., 1997; Jones et al., 2001):

$$
S I_{j}=\left(\sum p_{i, j} \cdot W_{i, j}\right) / 300
$$

317 where $p_{i, j}$ is the percentage of trees classified in a certain damage class, $W_{i, j}$ is the damage scalar ( 0 318 for no damage D0, 1 for D1, 2 for D2 and 3 for total damage D3), $i$ is the damage class and $j$ is the 

experienced by the tree species.

Ordinal logistic regression (OLR; Kleinbaum and Klein, 2010; Harell, 2001) was used for modelling the probabilities of each of the four ice damage categories (D0 - D3) in the dependence on the three groups of explanatory variables (Table 1). The meteorological estimate of ice storm intensity (DINT) was included in the model as the main explanatory variable. The second group of explanatory variables considered individual tree attributes: tree species (SPEC), diameter at breast height (DBH) and social status (SS). The third group of explanatory variables considered the stand and geographic properties of each examined plot: Gini index (GINI), Shannon-Wiener index (SW), quadratic mean diameter (QMD), elevation (ELV), slope (SLP) and topographic position of the plot (TOP). After including these variables in the OLR mixed model as fixed effects, the random effect of plots was not statistically significant. Thus, we assumed that this group of variables explain between-plot variability well enough that there was no need to consider the random effect of a plot in the model. The OLR assumptions testing and the model fitting were applied in the R statistical software (R Core Development Team, 2019) using the rms package (Harrell, 2017). The tree ice damage (TDAM) was an ordinal response variable with four categories. With the OLR model, the probabilities of each ice damage category were estimated considering the presented explanatory variables. The OLR model enables simultaneous estimation of the probabilities of occurrence and severity of ice damage. We fitted the OLR with a proportional odds model. For the response variable $Y$ with levels $0,1, \ldots, \mathrm{k}$, the cumulative probability for the $\mathrm{j}$-th damage class, where $\mathbf{j}=1, \ldots, k$, occurs conditionally on $\mathbf{X}$, and is expressed as:

$$
\mathrm{P}(\mathrm{Y} \geq \mathrm{j} \mid \mathbf{X})=\frac{1}{1+\exp \left(-\left(\alpha_{\mathrm{j}}+\mathbf{X} \beta\right)\right)}
$$

341 where $\alpha_{\mathrm{j}}$ is a category specific intercept, $\boldsymbol{X} \beta=\beta_{1} X_{1}+\beta_{2} X_{2}+\ldots+\beta_{p} X_{p}$ where $\beta_{\text {a are regression }}$ 342 coefficients for each of regressors $X_{\mathrm{i}}(\mathrm{i}=1, \ldots, \mathrm{p})$. The OLR model was fitted to our data using the $\operatorname{Irm}()$ R function (Harrell, 2017). 
Table 1: Variables included in the modelling procedure measured or evaluated on the sampling plot or tree

categories are given

\begin{tabular}{|c|c|c|c|c|c|c|}
\hline Variables & & $\begin{array}{l}\text { Variable } \\
\text { type }\end{array}$ & \multicolumn{3}{|c|}{ Categories / statistics } & $\begin{array}{l}\text { Data } \\
\text { scale }\end{array}$ \\
\hline \multicolumn{7}{|l|}{ Response variable } \\
\hline Tree ice damage & TDAM & categorical & \multicolumn{3}{|c|}{$\begin{array}{l}\text { D0 - trees with no visual damage, } \\
\text { D1 - trees with moderate damage, } \\
\text { D2 - trees with severe damage, } \\
\text { D3 - trees with total damage, }\end{array}$} & tree \\
\hline \multicolumn{7}{|l|}{ Categorical independent variables } \\
\hline Disturbance intensity & DINT & categorical & \multicolumn{3}{|c|}{$\begin{array}{l}\text { DINT0 - no ice }(\leq 0.1 \mathrm{~mm}) \text {, } \\
\text { DINT1 - low intensity with thin ice } \\
\text { accretion ( }>0.1-5 \mathrm{~mm}) \text {, } \\
\text { DINT2 - moderate intensity with } \\
\text { thick ice accretion ( }>5-20 \mathrm{~mm}) \text {, } \\
\text { DINT3 - severe to extreme intensity } \\
\text { with very thick ice accretion (>20 } \\
\mathrm{mm}) \text {, }\end{array}$} & plot \\
\hline Tree species or group of species & SPEC & categorical & \multicolumn{3}{|c|}{$\begin{array}{l}\text { 1-Abies alba, } \\
\text { 2-Picea abies, } \\
\text { 3-Pinus sylvestris \& P.nigra, } \\
\text { 4-Fagus sylvatica, } \\
\text { 5-Quercus petraea, } \\
\text { 6-Acer pseudoplatanus \& A. } \\
\text { platanoides, }\end{array}$} & tree \\
\hline Social status of the tree & SS & categorical & \multicolumn{3}{|c|}{$\begin{array}{l}\text { SS1 - predominant or dominant } \\
\text { tree, } \\
\text { SS2 - codominant or intermediate } \\
\text { tree, } \\
\text { SS3 - suppressed understorey tree }\end{array}$} & tree \\
\hline Topographic position of the plot & TOP & binary & \multicolumn{3}{|c|}{$\begin{array}{l}0 \text { - plane } \& \text { foot of the hills, } \\
1 \text { - slope } \& \text { ridge }\end{array}$} & plot \\
\hline Continuous independent variables & & & Mean & Min - Max & CV & \\
\hline Elevation of the plot center ( $\times 100 \mathrm{~m}$ a.s.l.) & ELV & scale & 6.41 & $2.03-13.00$ & 0.385 & plot \\
\hline Slope of the plot $\left({ }^{\circ}\right)$ & SLP & scale & 18.2 & $0-50$ & 0.574 & plot \\
\hline Diameter at breast height $(\mathrm{cm})$ & $\mathrm{DBH}$ & scale & 28.6 & $10-112$ & 0.506 & tree \\
\hline Quadratic mean diameter $(\mathrm{cm})$ & QMD & scale & 29.8 & $12.3-66.3$ & 0.318 & plot \\
\hline Gini index & GINI & scale & 0.3025 & $0.005-0.790$ & 0.372 & plot \\
\hline Shannon-Wiener index & SWI & scale & 0.6515 & $0-1.6543$ & 0.606 & plot \\
\hline
\end{tabular}


In order to fit the OLR, the data have to meet the proportional odds assumption (Harell, 2001). This means that the logit transformation of the ordinal dependent variable $Y$ has to express a linear response on a continuous explanatory variable $X_{i}$. This assumption was graphically tested, and if the response was not approximately linear, restricted cubic splines were used to adequately transform the continuous explanatory variable. A nonlinear response was found for ELV, SLP and SWI. The suitable number of knots at restricted cubic splines for each of three explanatory variables was chosen on the basis of the likelihood ratio test of nested models using the function Irtest().

Our assumption was that the influence of ELV, SLP and DBH on the probabilities of TDAM categories is not the same across all DINT categories; thus, the interaction terms between DINT and the three listed continuous variables were included in the model.

In the process of the model validation which was performed by the application of the bootstrap procedure and the $k$-fold cross-validation method using the function validate(), two explanatory variables TOP and QMD were excluded from the final model. The relative importance of the predictors in the final model was presented on the basis of the ANOVA analysis with the partial $\chi^{2}$ Wald statistics, testing the association of each predictor with the response variable, adjusted for all other predictors. The measure of relative importance of each component in the final model was computed as ( $\chi^{2}$-statistic - degrees of freedom) (Harrell, 2001).

\section{Results}

The ice storm damaged $31 \%$ of trees in the study area. A similar proportion of trees experienced moderate and total damage ( $12.2 \%$ and $13.9 \%$, respectively), while severe damage was less frequent (5.2\%). Based on the results in Table 2 and Figure 2, the most resistant species appeared to be Quercus among broadleaves and Abies among conifers; some tree species experienced a lower SI than these two tree species (Appendix, Table A1) but were rare and appeared only sporadically. 
more than half of damaged Abies trees were totally damaged, Quercus trees mainly experienced a much higher proportion of moderate damage. However, when damage rates per ice storm intensity categories were considered (Figure 3), Abies was the most resistant species, with the lowest damage rates across all ice storm intensity categories, while Quercus experienced similar damage rates to Fagus at severe to extreme ice storm intensity (DINT3), but lower damage rates at lower ice storm intensities. By comparison, Fagus, the most frequent tree species, experienced higher proportions in all damage classes than Abies and partly Quercus, while Picea experienced a much higher proportion of total and moderate damage, but a similar proportion of severe damage. The highest SI of 0.62 was observed for Pinus, making it the most susceptible tree species to ice damage.

Table 2: Ice damage per tree species, showing the number of surveyed trees $\mathrm{N}$, the calculated susceptibility index SI for different ice storm intensities - low intensity DINT1, moderate intensity DINT2, severe to extreme intensity DINT3 - and SloveraLL irrespective of ice storm intensity

\begin{tabular}{|c|c|c|c|c|c|}
\hline Tree species & $\mathrm{N}$ & $S I_{D I N T=1}$ & SIDINT=2 & SIDINT $=3$ & SloveraLL \\
\hline Abies alba & 836 & 0.01 & 0.19 & 0.13 & 0.14 \\
\hline Acer sp. ${ }^{*}$ & 571 & 0.12 & 0.17 & 0.43 & 0.24 \\
\hline Fagus sylvatica & 4216 & 0.13 & 0.27 & 0.42 & 0.23 \\
\hline Picea abies & 3108 & 0.07 & 0.28 & 0.47 & 0.28 \\
\hline Pinus sp. ${ }^{*}$ & 290 & 0.16 & 0.13 & 0.83 & 0.62 \\
\hline Quercus petraea & 330 & 0.09 & 0.09 & 0.33 & 0.11 \\
\hline other broadleaves ${ }^{* *}$ & 2029 & 0.12 & 0.14 & 0.37 & 0.18 \\
\hline other conifers $^{* * *}$ & 34 & 0.00 & 0.20 & 0.25 & 0.21 \\
\hline All species & 11414 & 0.11 & 0.22 & 0.43 & 0.23 \\
\hline
\end{tabular}
other broadleaves: Carpinus betulus, Ostrya carpinifolia, Fraxinus excelsior, Alnus glutinosa, Castanea sativa, Fraxinus ornus, etc. 


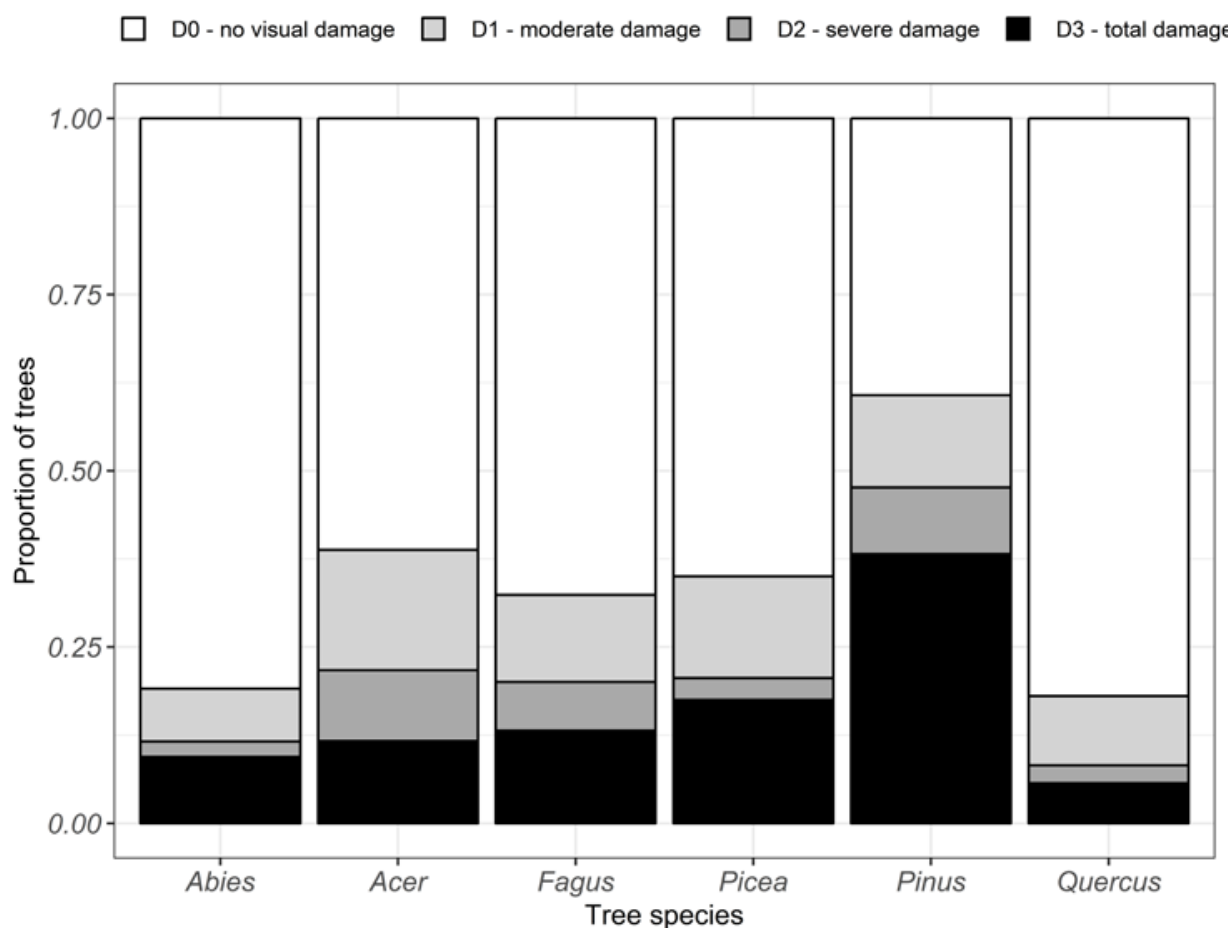

394

Figure 2: Proportions of trees with different ice damage classes (D0-D3) by tree species

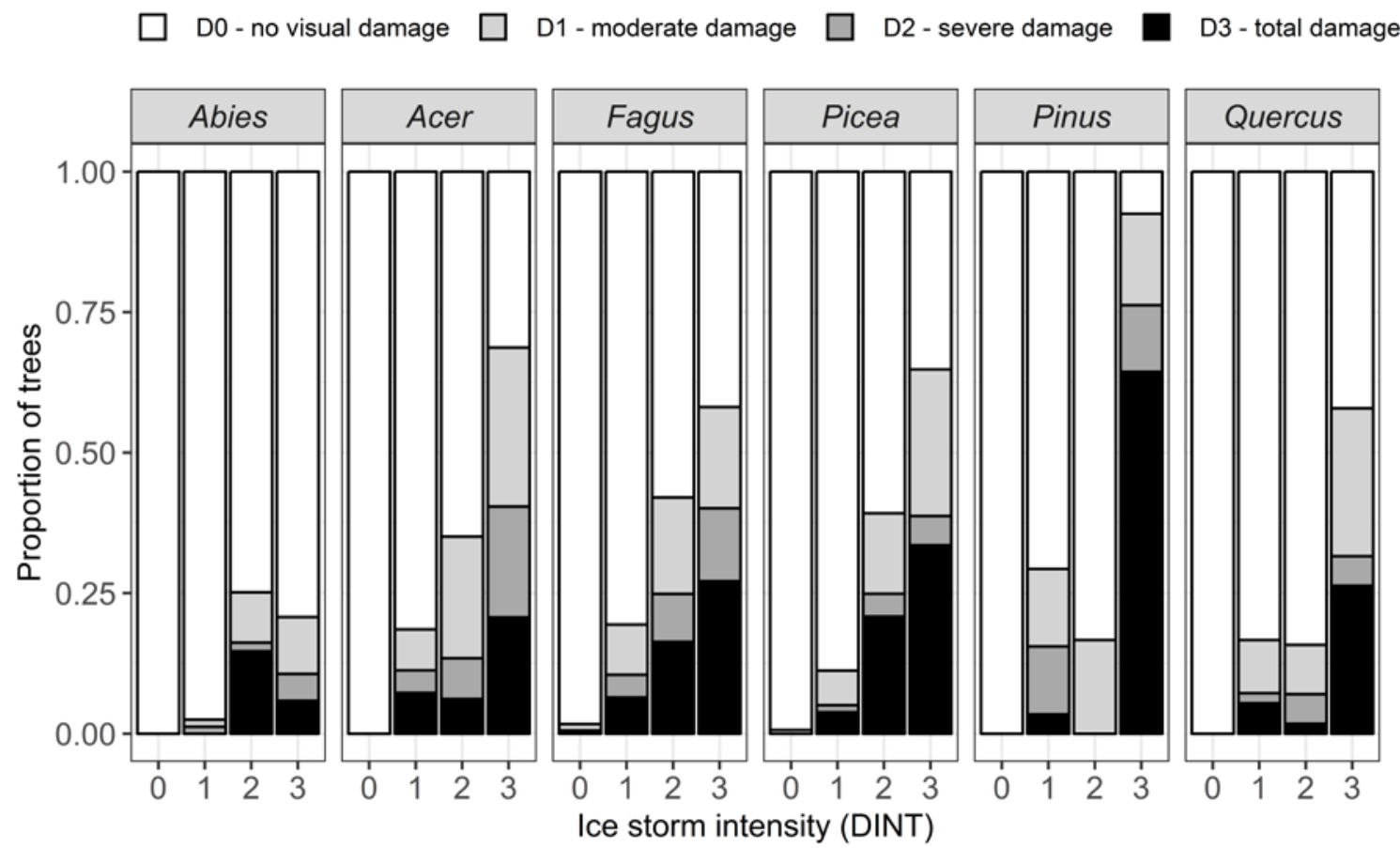

397 Figure 3: Proportions of trees with different ice damage classes (D0-D3) by tree species, differentiated by ice storm intensity categories (DINT) 
The final OLR model of ice damage (TDAM) included 8 predictors: DINT, ELV, SLP, DBH, SPEC, SS, GINI and SWI. The non-linear dependence of TDAM on ELV, SLP and SWI was considered using restricted cubic splines with five knots. The interactions between DINT and ELV, SLP, and DBH were also considered in the OLR model (Supplementary Material, Table SM2). Bootstrapping the model showed no serious problems with overfitting: the original sample Somer's rank correlation between predicted probabilities and observed response $\left(D_{x y}\right)$ was 0.6541 , while the corrected $D_{x y}$ on the basis of optimism from the bootstrap procedure was 0.6477 , the corrected slope of the overall logistic calibration equation was 0.9797 , and the maximum absolute difference in predicted and calibrated probabilities $\left(E_{\max }\right)$ was 0.0075 . The R-square value of the model was 0.404 .

The ANOVA results showed that the ice storm intensity DINT was the most important predictor of ice storm damage to trees (Figure 4); the second most important predictor was elevation and its interaction with DINT, followed by tree species, SLP, SWI, DBH and other predictors and their interactions. Considering all other predictors in the model, Quercus, Picea, Acer, Fagus and Pinus were $3.03,3.09,3.59,4.26$ and 8.03 times more likely to increase in damage class than Abies, respectively.

We were particularly interested in relations between ice storm intensity DINT, tree species SPEC and DBH since this relation is of utmost importance for forest practice. Thus, we calculated the cumulative predicted probabilities of occurrence of ice damage classes (Figure 5) and the predicted probabilities (Figure 6) considering all three predictors of interest, while all others were held constant at their mean or most frequent category. In a low intensity ice storm (DINT1), the damage occurrence probability was almost constant with respect to DBH. It was the lowest for Abies and the highest for Pinus. At this ice storm intensity, moderate damage was the most likely to occur for all tree species (Figure 4), but only Pinus exceeded the $10 \%$ probability. The probability of total damage occurrence was lower than $5 \%$, while Pinus was the only species that exceeded this threshold probability. For all tree species severe damage was less likely to occur than moderate or total damage. 


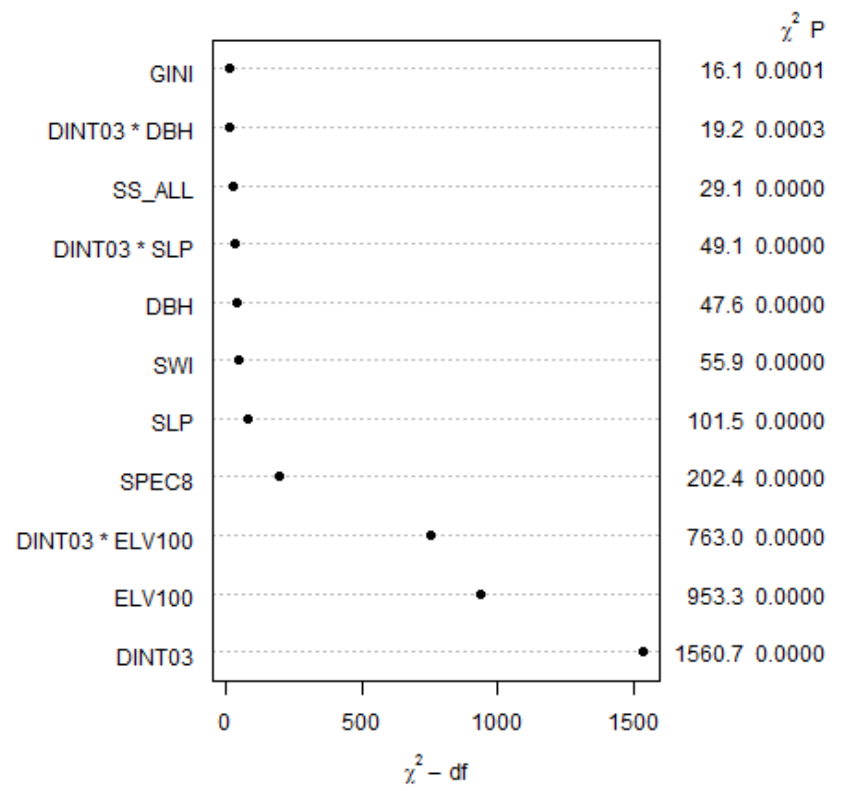

425

426 Figure 4: The relative importance of the predictors and their interactions within the ordinal logistic model

427 estimated by the ANOVA with the difference between partial $\chi 2$-values and degrees of freedom df (i.e. $\chi 2-\mathrm{df})$

428 (Harell, 2001)

429

430

At an extreme ice storm intensity (DINT3), once again Abies experienced the lowest damage

431

occurrence probability (at most $50 \%$ at a DBH of $10 \mathrm{~cm}$ ), while Pinus and Fagus experienced the

highest, reaching more than $85 \%$ and $75 \%$ (both at a DBH of 10-27 cm), respectively. Even trees of $100 \mathrm{~cm}$ in dbh of these two species were subjected to more than $58 \%$ and $42 \%$ probability of damage occurrence, respectively, while Abies trees of the same size experienced only $15 \%$ probability of damage occurrence. Small- to medium-sized trees of most tree species experienced a higher probability of total damage than of moderate or severe damage; the thresholds of mean dbh at which the probabilities of moderate damage exceeded those of total damage were $57 \mathrm{~cm}, 66 \mathrm{~cm}$, $50 \mathrm{~cm}, 98 \mathrm{~cm}$ and $48 \mathrm{~cm}$ for Acer, Fagus, Picea, Pinus and Quercus, respectively. The exception was Abies, which was more likely to experience moderate damage than total or severe damage at all dbh values. 


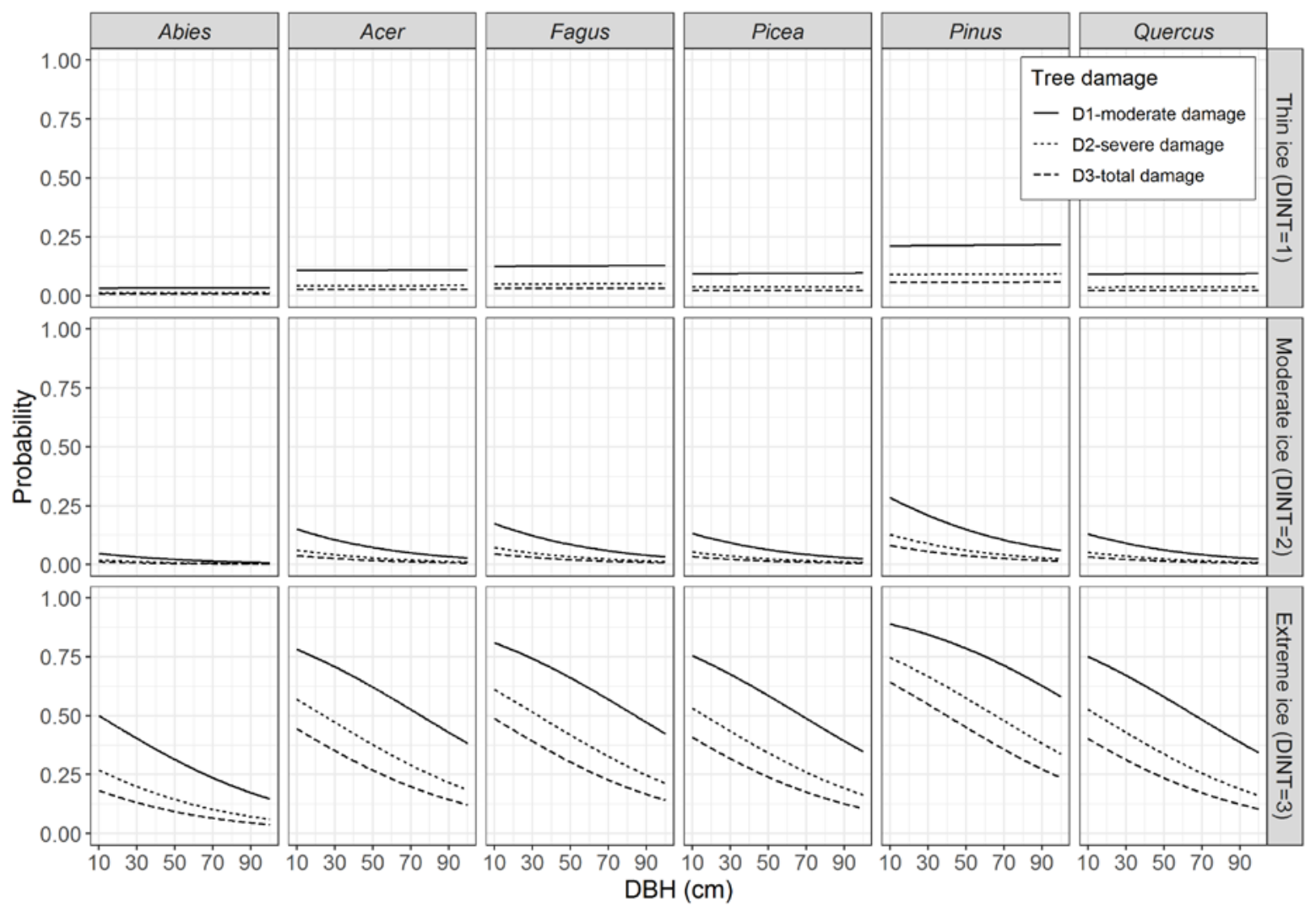

Figure 5: Cumulative probabilities of damage occurrence for predominant and dominant trees of tree species in relation to tree size (DBH) and ice storm intensity (DINT); other continuous predictors were held constant at

their means

446

447 For forest practice, the influence of social status of a tree (SS) and tree size (GINI) and tree species diversity (SWI) are important as well (see Supplementary material). We observed only minor differences in the probabilities of damage occurrence and the damage types between dominant, codominant and suppressed understory trees; for all tree species, understorey trees experienced the highest damage probabilities. The influences of GINI and SWI were similar, showing decreasing probabilities of damage with increasing tree size or species diversity. At severe to extreme ice storm intensity DINT3, the probability of total damage decreased markedly with increasing stand diversity. 


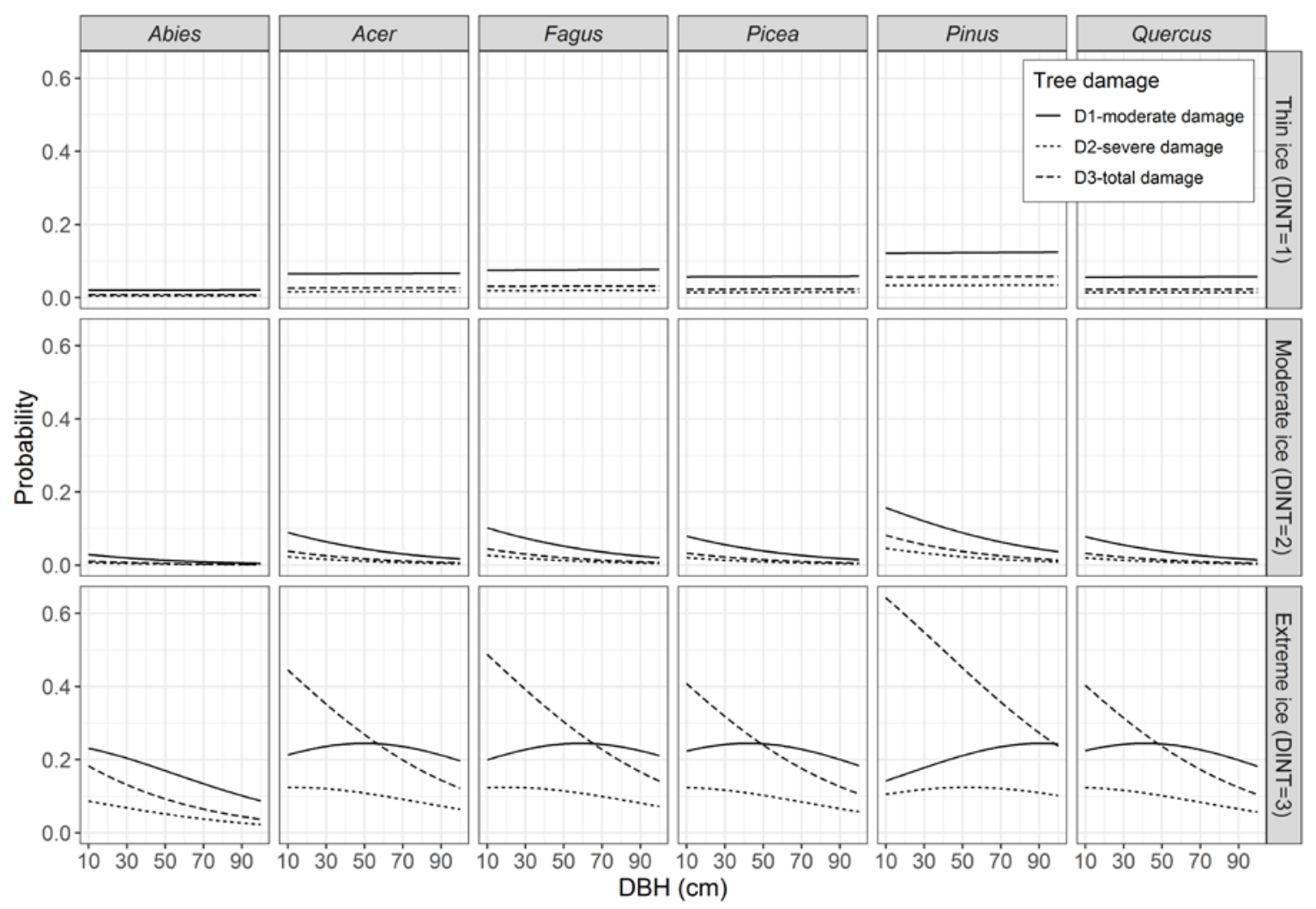

Figure 6: Predicted probabilities of moderate (D1), severe (D2) and total damage (D3) of tree species in relation to tree size (DBH) and ice storm intensity (DINT); only trees with social status SS1 (predominant and dominant) were considered; other continuous predictors were held constant at their means

\section{Discussion}

This study is probably one of the first in Europe to assess ice storm intensity based on measured meteorological data and using it to examine species-specific susceptibility to ice damage; previous studies used proxies based on ice damage on the studied plots (e.g. Nagel et al., 2016). We considered four levels of ice storm intensity, whereas most other studies have focused on relatively small forest areas, assuming constant ice storm intensity. In addition, our approach provided an

467 insight into the patterns of damage susceptibility of tree species in relation to ice accretion of different thicknesses. 
Ice storm intensity was by far the most important predictor of ice damage on trees; its relative importance in the OLR model was much higher than that of tree species. Ice accumulation was found to be a major predictor of bending also in loblolly pines (Pinus taeda) in the southeastern United States (Aubrey et al., 2007) and of light and moderate to severe crown damage and uprooting in unmanaged mature forest stands in Central Europe (Nagel et al., 2016). In addition, Proulx and Greene (2001) demonstrated that ice accumulation was the primary explanatory variable of individual tree damage occurrence and damage type. Lafon (2004) showed, based on six studies on ice-storm disturbance, that the proportion of trees damaged increased linearly with ice thickness (in $\mathrm{mm}$ ), with a slope factor of 0.0154 . Our results were similar; however, our study indicated a nonlinear relationship. Ice accretion of $>\mathbf{2 0} \mathrm{mm}$ represented the threshold for severe damage to trees in the study. Similarly, Rustad and Campbell (2012) found that ice accretion of 7-12 mm caused significant canopy damage in the northern hardwoods, resulting in a significant increase of fine and coarse woody debris and a significant increase in leaf-on canopy openness, but only $10 \%$ of trees suffered severe crown damage or breakage. In our case this percentage was more than twice as high (Figure 3).

There are some shortcomings in the procedure for calculating ice storm intensity, especially in the assessment of ice thickness within the DINT categories. However, including the validated ice storm intensity in the ice damage model showed its high importance for damage to trees. The ice load thickness on tree crowns is strongly affected by the local environment and microclimate conditions and thus usually varies even at small scales within a stand, and to an even greater extent on a landscape scale across the ice storm track (Boerner et al., 1988). Although Picea and Pinus are more susceptible to ice damage than broadleaved species, the opposite has been found for some other conifers, namely Abies and Larix (see Supplementary material). The rate of ice damage on Abies was the second lowest among the analysed tree species. However, when Abies is damaged, total damage quite frequently occurs, mainly due to severe crown damage (i.e. top breakage) or stem breakage. Yet, for Abies the probability of occurrence of at least 
moderate damage to trees was the lowest among all analysed tree species. A similar finding was reported by Nagel et al. (2016) for unmanaged mature forests. In Nebraska, USA, Abies species were also found to have exceptional resistance (Evertson, 2007). It is possible that differences in wood traits between Abies and other species could be a reason for its low damage rate (Nykänen et al., 1997). Another possible reason might be a higher proportion of medium and large Abies trees in the analysed stands compared to other tree species. We found that the probability of ice damage decreased with increasing dbh. However, the SI value, when calculated only for trees smaller than 30 $\mathrm{cm}$ in dbh (results not shown), also indicated much lower susceptibility of Abies to ice damage compared to the other main tree species of the same dbh class.

Pinus was the most susceptible tree species to ice damage; it had the highest SI value by far and experienced the highest proportion of total damage (Table 2, Figure 2). It sustained mainly small and large branch breakage as well as stem breakage resulting in severe to total damage. Picea experienced the second highest rate of total damage among the main species; it can be classified as a relatively susceptible tree species to ice damage. A detailed study of ice damage in a location within our study area showed that Picea suffered mainly tree top breakage, causing moderate to severe damage (Šink, 2015). However, this is contradictory to the findings of Nagel et al. (2016), who recognized Picea as a less susceptible species to ice damage in the same study area. The fundamental difference is that they studied rather uneven-aged unmanaged stands with cohorts of large canopy trees, while we analysed stands irrespective of size evenness and management. In addition, their plots were intentionally located in severely damaged forest areas, while we included plots covering the entire gradient of ice storm intensity.

516 Among all coniferous tree species registered in our study, Larix decidua and non-native Pseudotsuga 517 menziesii were the most resistant ( $\mathrm{SI} \leq 0.10$; see Supplementary Material). However, their presence 518 is limited to a few small forest areas within the studied forest stands. In addition, the ice storm 519 occurred in February, when Larix was needleless, which might have additionally decreased its susceptibility to damage. Regardless, these results justify more research on both tree species. 
Fagus, the most frequent species in our study area, and Acer were the most susceptible to ice

522

523

524

525

526

527

528 damage among the main broadleaved species, whereas Quercus was among the least damaged tree species. A higher proportion of Fagus in forest stands was demonstrated to increase the occurrence probability and severity of ice damage in Hungary (Aszalós et al., 2012), while less damage was observed in stands with a higher proportion of Quercus (Kenderes et al., 2007). According to our study, several minor broadleaved tree species, which occur sporadically in forest stands (i.e. Ulmus glabra, Sorbus aucuparia, Sorbus aria), experienced heavy damage and can be characterized as highly susceptible to ice damage $(\mathrm{SI}>0.27$ ), while some other minor tree species (i.e. Carpinus betulus, Fraxinus excelsior, Quercus cerris, Robinia pseudoacacia, Salix spp., Sorbus torminalis, Tilia sp.) seem to be among the resistant tree species $(\mathrm{SI} \leq 0.13)$. As the sample for these species was rather small, these results should be interpreted with caution.

Several tree attributes, which were not directly studied in our analysis, can be related to species, namely deciduousness and evergreeness, growth form and crown architecture, mechanical properties of the wood, and intra-specific genetic variation. Since the majority of ice storm events in Central Europe occur between November and February (Carrière et al., 2000), the higher susceptibility of conifers may be related to their evergreen canopy and consequently larger surface area for ice accumulation (Lemon, 1961). However, for Abies, this factor seems to be less important in contributing to its susceptibility. Tree species differ in growth form and crown architecture, including crown form, fineness of branching, branch angle and arrangement, and crown symmetry, which may influence ice damage susceptibility (Cannell and Morgan, 1989; Smith, 2000). Nock et al. (2016) confirmed the key role of crown architecture in determining intra-crown patterns of ice accretion; higher and exterior branches accumulate more ice than lower and inner branches. If linked to differences in crown architecture between tree species, this could be a possible explanation for the differences found in our study. Furthermore, the mechanical properties of the wood determine the pliability of the limbs and stems, which importantly influence the resistance of 
tree species to ice damage (Bragg et al., 2003); pliability, however, is closely related to the diameter of a limb or stem.

The probability of ice damage decreased with tree size in terms of dbh, though its relevancy in the model was quite low. In general, larger trees appear to be more resistant to ice loads than smaller, often spindly trees. However, very small trees of $<5 \mathrm{~cm}$ dbh are often highly resilient to ice or snow damage since their supple boles are pliable enough to bend but not break under ice load, and after the ice melts, they usually straighten relatively quickly (Bragg, 2016). This pliability diminishes with increasing $\mathrm{dbh}$. This finding could be related to wood properties, such as modulus of rupture (MOR) and related maximum bending moment (RC), which are of crucial importance in branch, stem or root breakage (Bragg et al., 2003). Since RC depends on $\mathrm{dbh}^{3}$, it is higher in large trees with stronger wood; this is species specific, however. The larger size of trees may impart structural rigidity and hence lower pliability, but greater resistance to breakage (Amateis and Burkhardt, 1996). The latter is true only if the trees are not infected by wood-decay fungi or have not experienced any other injury or wood failure in the stem, branches or root system. Our results on the influence of tree dbh on the probability of ice damage are in accordance with the findings of Rebertus et al. (1997) and Rhoads et al. (2002), but in contrast to those of Nagel et al. (2016), who analysed unmanaged stands with an abundance of large trees. Also, Jones et al. (2001) found that plots dominated by large trees were more damaged than plots dominated by small trees. Several studies (e.g. Lafon, 2004; Nadrowski et al., 2014), however, found that ice storms predominantly affect trees of $15-20 \mathrm{~cm} \mathrm{dbh}$, in contrast to smaller and larger-sized trees.

Our study showed that tree size significantly influences the damage class; the probability of totally damaged trees was higher among small trees. Similar results were reported by Lafon (2004), who determined higher probabilities of bent boles and severe bole damage such as snapping in smalldiameter trees and higher probabilities of crown damage with increasing tree diameter. Several other studies (Proulx and Greene, 2001; Priebe et al., 2018) demonstrated that increasing tree diameter tends to shift ice damage from bending to crown loss; however, our data did not confirm 
this. In addition, the probability of a tree being uprooted increases with dbh if trees are growing on a slope (Nagel et al., 2016).

The social status of a tree had a significant but minor influence on ice damage probability. Our finding that trees occupying the predominant and dominant positions within the stand canopy experienced the lowest probability of damage was contrary to the findings of Rebertus et al. (1997) and Rhoades (1999). They reported much heavier damage in dominant trees than in suppressed trees. In our case, one of the possible explanations for the higher probability of damage among suppressed trees could be indirect damage caused by falling debris from injured canopy trees. Canopy trees increase the amount of shelter and prevent direct ice loading damage to suppressed trees, but also increase the probability of indirect damage due to the larger quantity of potential debris that could damage supressed trees (Priebe et al., 2018). In confirmation, Boerner et al. (1988) reported that a large Fagus grandifolia tree toppled and uprooted a number of suppressed understory trees downslope. However, indirect damage strongly depends on the species composition of the canopy layer (Priebe et al., 2018); if ice damage prone species are present there, the likelihood of indirect damage to suppressed understory trees is greater. Among stand variables, indices of species diversity (SWI) and heterogeneity of sizes (GINI) were included in the model of ice damage. Stands with lower species diversity (i.e. pure stands) suffered higher levels of ice damage than stands with higher species diversity (i.e. mixed stands), which is in accordance with other studies from Europe (Kenderes et al., 2007; Aszalós et al., 2012) and North America (e.g. Jones et al., 2001; Rhoads et al., 2002). The higher probability of ice damage in more homogenous stands in terms of species composition might be related to the fact that stands with low tree species diversity are usually comprised of Picea or Fagus, which are both moderately to 594 very susceptible species, and sometimes of Pinus, which is an extremely susceptible tree species. In 595 addition, pure stands are usually thinned more or less regularly to accelerate the radial growth of the remaining trees, which could add to the amount of ice damage experienced in these stands (e.g. 
have no effect on single tree damage due to ice loading or may have both negative and positive effects that cancel each other out at the scale of a single tree. The Gini index, which expresses the heterogeneity of tree sizes in a stand, was also recognized as a predictor, though its relevancy was lower than that of SWI. A tree's likelihood of being damaged is lower in more uneven-sized stands than in more even-sized stands. Moreover, uneven-sized stands may also signify increased resilience to natural disturbance due to the presence of trees of all sizes in a relatively small forest area. To our knowledge, our study is the first to demonstrate this relationship between stand heterogeneity in terms of tree size and ice damage, although it should be noted that stand age and stand height were reported as important predictors of ice damage (e.g. Aszalós et al., 2012). Among other stand variables, stand density has often been recognized as a determinant of ice damage, although Bragg et al. (2003) cited many conflicting reports on the effects of stand stocking. Generally, dense stands have been found to be more vulnerable to ice storms, where collision from falling neighbouring trees is an important risk factor (Cain and Shelton, 2002). Site conditions can be also an important determinant of ice damage severity. Higher damage rates have often been observed at higher elevations and on steeper slopes (e.g. Kenderes et al., 2007; Isaacs et al., 2014). Rhoads et al. (2002) found that ice accumulation and thus ice damage increased with elevation, but this relationship was best explained by a second-order polynomial regression. A similar result was found in our study (see Supplementary material), meaning that ice storms often impact only a specific elevation belt, which depends on the vertical temperature profile and the altitude of the border between warm and cold air layers. In our study, slope was a significant but not decisive predictor of ice damage. Steep slopes can be indicative of shallow soils, reducing the rooting depth and increasing vulnerability to uprooting. If the soil is highly saturated, the probability of uprooting is even greater (Nagel et al., 2016). The topographic position was not included in our model, but some researchers found that topographic features (e.g. valley bottoms, foothills, lower and upper slopes) are important for ice damage (e.g. Bruederle and Stearns, 1985; Rhoades, 1999). 
resulting in more frequent and severe damage (Warrillow and Mou, 1999). Among site variables, soil characteristics, such as soil depth and moisture, may be associated with ice damage (e.g. Rhoades, 1999), but were not included in our study because the available data were not of adequate quality.

627

\section{Conclusions}

Worldwide, there is a great deal of discussion about adaptation of forests to environmental changes. Several aspects of adaptation have been thoroughly studied, such as changes in the growth of different tree species, their health status, the impact of pathogens and insects, assisted migrations, etc., and knowledge on the resistance of tree species to natural disturbances is an additional tool for the adaptation of forests and forestry.

Our model of ice damage to trees could be used as a basis for adaptation of forest management in regions prone to ice storms. When stands in such areas are naturally or artificially regenerated, the creation of mixed stands must be a priority, and tree species resistant to ice damage should be promoted. Mixed stands with high species diversity were recognized to be more resistant to ice damage than less diverse stands. Abies alba among conifers and Quercus petraea among broadleaves seem to be the most suitable tree species to promote in Central Europe, but the same is also true for some other minority ice damage resistant species. If these species are regenerated naturally, they can be promoted through the length of the regeneration period (e.g. longer regeneration periods for promoting shade-tolerant species such as Abies alba or very short regeneration periods for promoting shade-intolerant Quercus petraea), but also through the size, shape and orientation of the regeneration areas. much less prone to ice damage. Thus, large-sized trees may represent the basis of resistance against

647 ice damage to stands and also of resilience since these trees usually fructify regularly and represent 648 a continuous seed source for new stands following ice storms. Having some large-sized trees in a 649 stand should significantly improve both the resistance and resilience to ice (and other) storms. The 

size (dbh) threshold is, however, species specific, but based on our results, a threshold of $50 \mathrm{~cm}$ could be suggested for all analysed tree species.

652 In relation to large-sized trees in stands, classical selective thinning (Schädelin, 1942; Boncina et al., 2007; also termed thinning from above, while in North America Smith et al. (1997) defined it as crown thinning) should be encouraged. In this type of thinning, the favoured trees (crop trees) are mainly from the dominants, exhibiting vigour, large crown of suitable shape and good stem quality. The removed trees (competitiors) are mainly from the codominants, but also dominants and intermediate trees, in order to open up the canopy and favour the growth and development of the crop trees (Schädelin, 1942; Smith et al., 1997). Such thinning has a positive long-term impact on 1) the radial growth of remaining trees, which increase faster in dbh (Boncina et al., 2007) and thus experience decreased probability of ice damage; 2) tree stability through a decreasing stem taper (i.e. $\mathrm{h} / \mathrm{dbh}$ ) over time; and 3) tree crown size which grows faster due to enlarged growing space as a result of harvested competitive trees. In the short term, however, selective thinning may reduce stand and tree resistance to abiotic disturbance due to the abundance of small gaps dispersed throughout the stand canopy, which reduce the support between neighbouring trees. occurs. In regions where ice storms occur frequently and are predicted to be even more frequent and intense, the above-mentioned and also other adaptive measures are urgently needed in order to adequately prepare forests for environmental changes and their consequences. This work was supported by Pahernikova ustanova.

672 
674 We are grateful to the Slovenia Forest Service for providing access to the forest inventory databases,

675 which made our study feasible. We would also like to thank the editors and two anonymous 676 reviewers for their constructive remarks which significantly improved the paper.

677

\section{Conflict of interest statement}

679 None declared.

680

681

\section{References}

682

Amateis, R.L. and Burkhart, H.E. 1996 Impact of heavy glaze in a loblolly pine spacing trial. South. J.

Appl. Forest., 20 (3), 151-155.

684

ARSO. 2014a Snow, glaze and precipitation between 30.1.2014 and 3.2.2014 (in Slovene). Slovenian Environment Agency: Ljubljana, 12 p. Url:

686

http://meteo.arso.gov.si/uploads/probase/www/climate/text/sl/weather_events/sneg-zled-

687 padavine_30jan-3feb2014.pdf

688

ARSO. 2014b [dataset] GIS database on the 2014 ice storm intensity. Slovenian Environment Agency:

689 Ljubljana.

690

Aszalós, R., Somodi, I., Kenderes, K., Ruff, J., Czúcz, B. and Standovár, T. 2012 Accurate prediction of

691 ice disturbance in European deciduous forests with generalized linear models: a comparison of fieldbased and airborne-based approaches. Eur. J. Forest Res., 131 (6), 1905-1915. Aubrey, D.P., Coleman, M.D. and Coyle, D.R. 2007 Ice damage in loblolly pine: Understanding the factors that influence susceptibility. Forest Sci., 53 (5), 580-589. observations. In: XIII International workshop on atmospheric icing of structures (IWAIS), p. 8-11. 

beech (Fagus sylvatica L.) forest stands in south-eastern Slovenia. Ann. For. Sci., 64, 47-57.

Bragg, D.C. 2016 Initial mortality rates and extent of damage to loblolly and longleaf pine plantations affected by an ice storm in South Carolina. For. Sci., 62 (5), 547-585.

703

Bragg, D.C., Shelton, M.G. and Zeide, B. 2003 Impacts and management implications of ice storms on

Cain, M.D., Shelton, M.G., 2002. Glaze damage in 13- to 18-yearold, natural, even-aged stands of

loblolly pines in southeastern Arkansas. In: Outcalt, K. (Ed.), Proceedings of the $11^{\text {th }}$ Biennial Southern 583.

Cannell, M.G.R. and Morgan, J. 1989 Branch breakage under snow and ice loads. Tree Physiol., 5 (3), 307-317.

Carrière, J.-M., Lainard, C., Le Bot, C. and Robart, F. 2000 A climatological study of surface freezing precipitation in Europe. Meteorol. Appl., 7 (3), 229-238.

Coder, K.D. 2015 Trees, Sites \& Ice Storms: Attributes Leading to Tree Damage, Failure, \& Mortality.

Cressie N. 1993 Statistics for Spatial Data, Revised Edition. Wiley Classics Library, 928 p.

Curtis, R.O. and Marshall, D.D. 2000 Technical note: Why quadratic mean diameter? Western J. Appl. Forest., 15 (3), 137-139. de Groot, M., Ogris, N. and Kobler, A. 2018 The effects of a large-scale ice storm event on the drivers 722 of bark beetle outbreaks and associated management practices. Forest. Ecol. Manag., 408, 195-201. Dolinar, M. 2005 Spatialisation of precipitation in different time scale. In Proceedings of Voltaire 
Dolinar, M. 2014 Production Of Climate Maps: Operational Issues And Challenges. In Proceedings of DailyMeteo.org/2014 Conference. Faculty of Civil Engineering, University of Belgrade Belgrade, Serbia, pp. 69-71.

Evertson, J. 2007 Susceptibility of trees to ice storm damage in the Great Plains. Nebraska Statewide Arboretum.

Frelich, L.E. 2002 Forest Dynamics and Disturbance Regimes: Studies from Temperate Evergreen-

Deciduous Forests. Cambridge University Press: Cambridge, 266 p.

Garson, G.D. 2016 Logistic Regression: Binomial and Multinomial, 2016 Edition. Statistical Associates Publishers: Asheboro, NC.

Ge, J., Xiong, G., Wang, Z., Zhang, M., Zhao, C., Shen, G., Xu, W. and Xie, Z. 2015 Altered dynamics of broad-leaved tree species in a Chinese subtropical montane mixed forest: the role of an anomalous extreme 2008 ice storm episode. Ecol. Evol., 5 (7), 1484-1493.

GURS, 2014. GIS databases of Republic of Slovenia. Ministry of the Environment and Spatial Planning. The Surveying and Mapping Authority of the Republic of Slovenia, Ljubljana. Harrell, F.E.J. 2001 Regression Modeling Strategies. With Applications to Linear Models, Logistic Regression, and Survival Analysis. Springer New York: New York. Harrell, F.E.J. 2017 rms: Regression Modeling Strategies. R package version 5.1-0. https://cran.rproject.org/package=rms. Hopkin, A.A., Williams, T., Sajan, R.J., Pedlar, J.H. and Nielsen, C. 2003 Ice storm damage to eastern Ontario forests: 1998-2001. Forest. Chron., 79, 47-53. Irland, L.C. 2000 Ice storms and forest impacts. Sci. Total Environ., 262 (3), 231-242. Isaacs, R.E., Stueve, K.M., Lafon, C.W. and Taylor, A.H. 2014 Ice storms generate spatially

747 heterogeneous damage patterns at the watershed scale in forested landscapes. Ecosphere, 5 (11), 114. 
Jones, J., Pither, J., DeBruyn, R.D. and Robertson, R.J. 2001 Modeling ice storm damage to a mature, mixed-species hardwood forest in eastern Ontario. Ecoscience, 8 (4), 513-521.

Kämäräinen, M., Hyvärinen, O., Jylhä, K., Vajda, A., Neiglick, S., Nuottokari, J. et al. 2017 A method to estimate freezing rain climatology from ERA-Interim reanalysis over Europe. Nat. Hazards Earth Syst. Sci., 17 (2), 243-259.

Kenderes, K., Aszalós, R., Ruff, J., Barton, Z. and Standovár, T. 2007 Effects of topography and tree stand characteristics on susceptibility of forests to natural disturbances (ice and wind) in the Börzsöny Mountains (Hungary). Community Ecol., 8 (2), 209-220.

Kleinbaum, D.G. and Klein, M. 2010 Ordinal Logistic Regression. In Logistic Regression: A SelfLearning Text. Kleinbaum, D.G. and Klein, M. Springer New York, New York, NY, pp. 463-488.

Klima, K. and Morgan, M.G. 2015 Ice storm frequencies in a warmer climate. Climatic Change, 133, $209-222$.

Klopcic, M. and Boncina, A. 2010 Patterns of tree growth in a single tree selection silver fir-European beech forest. J. Forest Res., 15 (1), 21-30.

Kuhn, M. and contributions from Wing, J., Weston, S., Williams, A., Keefer, C., Engelhardt, A., Cooper, T., Mayer, Z., Kenkel, B., the R Core Team, Benesty, M., Lescarbeau, R., Ziem, A., Scrucca, L., Tang, Y., Candan, C., and Hunt, T. 2016 caret: Classification and Regression Training. R package version 6.0-73. https://cran.r-project.org/package=caret.

Lafon, C.W. 2004 Ice-storm disturbance and long-term forest dynamics in the Adirondack Mountains. J. Veg. Sci., 15 (2), 267-276.

Lemon, P.C. 1961 Forest ecology of ice storms. B. Torrey Bot. Club, 88 (1), 21-29

Makkonen, L. 2000 Models for the growth of rime, glaze, icicles and wet snow on structures. Phil. Trans. R. Soc. Lond. A, 358, 2913-2939.

Miller-Weeks, M., Eagar, C. and Petersen, C.M. 1999 The Northeastern ice storm 1998: A forest damage assessment. NEFA - the State Foresters of New York, Vermont, New Hampshire, and Maine, cooperating with the USDA Forest Service, State and Private Forestry: New Hampshire. 
Nadrowski, K., Pietsch, K., Baruffol, M., Both, S., Gutknecht, J., Bruelheide, H., Heklau, H., Kahl, A., Kahl, T., Nicklaus, P., Kröber, W., Liu, X., Mi, X., Michalski, S., von Oheimb, G., Purschke, O., Schmid, B., Fang, T., Welk, E. and Wirth, C. 2014 Tree species traits but not diversity mitigate stem breakage in a subtropical forest following a rare and extreme ice storm. Plos One, 9 (5), 1-7. Nagel, T.A., Firm, D., Rozenbergar, D. and Kobal, M. 2016 Patterns and drivers of ice storm damage in temperate forests of Central Europe. Eur. J. Forest Res., 135 (3), 519-530.

Nagel, T.A., Mikac, S., Dolinar, M., Klopcic, M., Keren, S., Svoboda, M. et al. 2017 The natural disturbance regime in forests of the Dinaric Mountains: A synthesis of evidence. Forest Ecol. Manag., $388,29-42$.

Nielsen, C., Van Dyke, O. and Pedlar, J. 2003 Effects of past management on ice storm damage in hardwood stands in eastern Ontario. Fro. Chron. 79, 70-74.

Nock, C.A., Lecigne, B., Taugourdeau, O., Greene, D.F., Dauzat, J., Delagranges, S., Messier, C. 2016 Linking ice accretion and crown structure: towards a model of the effect of freezing rain on tree canopies. Annals Bot., 117: 1163-1173.

Nykänen, M.-L., Peltola, H., Quine, C., Kellomäki, S. and Broadgate, M. 1997 Factors affecting snow damage of trees with particular reference to European conditions. Silva Fenn., 31 (2), 193-213.

Oliver, C.D. and Larson, B.C. 1996 Forest Stand Dynamics. Wiley: New York, 520 p.

Pile, L.S., Maier, C.A., Wang, G.G., Yu, D. and Shearman, T.M. 2016 Responses of two genetically superior loblolly pine clonal ideotypes to a severe ice storm. Forest Ecol. Manag., 360, 213-220. Poljanec, A. 2014 The assessment of damages in forest stands and of the amount of sanitary harvests due to the 2014 ice storm (in Slovene). Slovenia Forest Service: Ljubljana.

Priebe, J.E., Powers, M.D. and Cole, E.C. 2018 Species, tree size and overstory environment affect likelihood of ice storm damage to understory trees in a mature Douglas-fir forest. Forest Ecol. Manag., 409, 777-788.

Proulx, O.J. and Greene, D.F. 2001 The relationship between ice thickness and northern hardwood tree damage during ice storms. Can. J. Forest Res., 31 (10), 1758-1767. 

project.org.

Rebertus, A.J., Shifley, S.R., Richards, R.H. and Roovers, L.M. 1997 Ice storm damage to an oldgrowth oak-hickory forest in Missouri. Am. Midl. Nat., 137 (1), 48-61.

807 Rhoades, R.W. 1999 Ice storm damage in a Small Valley in southwestern Virginia. Castanea, 64 (3), $243-251$

Rhoads, A.G., Hamburg, S.P., Fahey, T.J., Siccama, T.G., Hane, E.N., Battles, J. et al. 2002 Effects of an intense ice storm on the structure of a northern hardwood forest. Can. J. Forest Res., 32 (10), 1763-

8111775.

812 Rustad, L.E., Campbell, J.L. 2012 A novel ice storm manipulation experiment in a northern hardwood 813 forest. Can. J. Forest Res., 42: 1810-1818.

814 Schädelin W. 1942. Die Auslesedurchforstung als Erziehungsbetrieb höchster Wertleistung (in 815 German), Bern, $147 \mathrm{p}$.

816 Schelhaas, M.J., Nabuurs, G.J. and Schuck, A. 2003 Natural disturbances in the European forests in 817 the 19th and 20th centuries. Glob. Change Biol., 9 (11), 1620-1633.

818 Seidl, R., Thom, D., Kautz, M., Martin-Benito, D., Peltoniemi, M., Vacchiano, G. et al. 2017. Forest

819 disturbances under climate change. Nat. Clim. Chang., 7, 395-402.

820 Slovenia Forest Service. 2014 [dataset] Forest Inventory Database. Slovenian Forest Service:

821 Ljubljana, Slovenia.

822 Slovenia Forest Service. 2018 [dataset] Timber Harvest Database. Slovenian Forest Service: Ljubljana, 823 Slovenia.

824 Šimić Milas, A., Rupasinghe, P., Balenović, I., Grosevski, P. 2015 Assessment of Forest Damage in 825 Croatia using Landsat-8 OLI Images. South-east Eur. Forest., 6 (2): 159-169. 
Sinjur, I., Vertačnik, G., Likar, L., Hladnik, V., Miklavčič, I. and Gustinčič, M. 2014 Ice storm in Slovenia in January and February 2014 - Spatial and temporal variability in weather across the dinaric landscapes in Slovenia (in Slovene). Gozdarski vestnik, 72 (7-8), 299-309.

Šink, M. 2015 Assessment of the forest stands in the Oselica forest district after ice storm in 2014. B. Sc. Thesis (Professional Study Programme): Ljubljana.

Smith, W.H. 2000 Ice and forest health. North. J. Appl. Forest., 17 (1), 16-19.

Smith, D.M., Larson, B.C., Kelty, M.J. and Aston, P.M.S., 1997. The Practice of Silviculture. Applied Forest Ecology. Ninth Edition. John Wiley \& Sons, Inc., New York, USA, 537 p.

Spellerberg, I.F. 2008 Shannon-Wiener Index. In Encyclopedia of Ecology. B.D. Fath (ed.), Academic Press, Oxford, pp. 3249-3252.

Tveito, O.E., Bertalanič, R., Bihari, Z., Dobesch, H., Dolinar, M. 2008 Spatialisation of climatological and meteorological information with the support of GIS (Working Group 2). In The use of geographic information systems in climatology and meteorology: COST action 719. Office for official publication of the EC, Luxemburg, pp. 36-163.

Vertačnik, G., Dolinar, M., Sinjur, I. and Gustinčič, M. 2015 Meteorological conditions during the ice storm causing glaze ice at the end of January and the beginning of February 2014 (in Slovene). Ujma, 29, 149-173.

Warrillow, M. and Mou, P. 1999 Ice storm damage to forest tree species in the Ridge and Valley Region of southwestern Virginia. J. Torrey Bot. Soc., 126 (2), 147-158.

Weiner, J. and Solbrig, O.T. 1984 The meaning and measurement of size hierarchies in plant populations. Oecologia, 61, 334-336.

Zarnovican, R. 2001 Glaze damage in a young yellow birch stand in southern Quebec, Canada. North. J. Appl. Forest., 18 (1): 14-18.

Zhou, B., Gu, L., Ding, Y., Shao, L., Wu, Z., Yang, X. et al. 2011 The great 2008 Chinese ice storm: Its socioeconomic-ecological impact and sustainability lessons learned. B. Am. Meteorol. Soc., 92 (1), 47-60. 

Ice storm damage to trees in mixed Central European forests: damage patterns, predictors and susceptibility of tree species Online supplementary material

Matija Klopčič , Aleš Poljanec, Mojca Dolinar, Damijana Kastelec and Andrej Bončina *Corresponding author email: matija.klopcic@bf.uni-li.si

The Online Supplementary Material supplements the methodology (Figure SM1) and results of the paper (Tables SM1 \& SM2, Figures SM2-7) and contributes to better understanding of the ice storm damage modelling and the obtained results. 
Table SM1: The list of tree species registered on surveyed permanent sampling plots $(n=960)$ with their grouping into eight main groups of tree species, showing also the number of trees $(\mathrm{N})$, the share of trees per damage class (D0 - tree with no damage, D1 - trees with moderate damage, D2 - trees with severe damage, D3 - trees with total damage), and the susceptibility index SlovERAL, calculated irrespective of the ice storm intensity

\begin{tabular}{|c|c|c|c|c|c|c|c|}
\hline \multirow{2}{*}{ Tree species } & \multirow{2}{*}{$\begin{array}{c}\text { Group of } \\
\text { tree species }\end{array}$} & \multicolumn{6}{|c|}{ Share of trees per damage class (\%) } \\
\hline & & $\mathrm{N}$ & DO & D1 & D2 & D3 & SloveraLL \\
\hline Abies alba & 1 & 836 & 80.62 & 7.42 & 2.15 & 9.81 & 0.14 \\
\hline Acer campestre & 8 & 56 & 69.64 & 14.29 & 3.57 & 12.50 & 0.20 \\
\hline Acer platanoides & 6 & 22 & 68.18 & 4.55 & 4.55 & 22.73 & 0.27 \\
\hline Acer pseudoplatanus & 6 & 549 & 61.93 & 17.12 & 10.02 & 10.93 & 0.23 \\
\hline Acer tataricum & 8 & 51 & 76.47 & 19.61 & 3.92 & 0.00 & 0.09 \\
\hline Alnus glutionsa & 8 & 171 & 61.99 & 19.88 & 8.77 & 9.36 & 0.22 \\
\hline Alnus incana & 8 & 26 & 84.62 & 0 & 3.85 & 11.54 & 0.14 \\
\hline Betula pendula & 8 & 40 & 75.00 & 12.50 & 0 & 12.50 & 0.17 \\
\hline Carpinus betulus & 8 & 546 & 80.95 & 8.42 & 3.30 & 7.33 & 0.12 \\
\hline Castanea sativa & 8 & 116 & 81.90 & 6.03 & 3.45 & 8.62 & 0.13 \\
\hline Fagus sylvatica & 4 & 4216 & 67.77 & 12.07 & 6.95 & 13.21 & 0.22 \\
\hline Fraxinus excelsior & 8 & 157 & 78.98 & 11.46 & 3.18 & 6.37 & 0.12 \\
\hline Fraxinus ornus & 8 & 142 & 69.72 & 8.45 & 7.04 & 14.79 & 0.22 \\
\hline Juglans regia & 8 & 13 & 38.46 & 53.85 & 0 & 7.69 & 0.26 \\
\hline Larix decidua & 7 & 13 & 76.92 & 15.38 & 0 & 7.69 & 0.13 \\
\hline Ostrya carpinifolia & 8 & 295 & 74.24 & 9.83 & 5.08 & 10.85 & 0.18 \\
\hline Picea abies & 2 & 3108 & 64.77 & 14.22 & 3.02 & 17.99 & 0.25 \\
\hline Pinus nigra & 3 & 78 & 80.77 & 6.41 & 7.69 & 5.13 & 0.12 \\
\hline Pinus sylvestris & 3 & 212 & 25.94 & 14.62 & 9.43 & 50.00 & 0.61 \\
\hline Populus tremula & 8 & 35 & 68.57 & 17.14 & 5.71 & 8.57 & 0.18 \\
\hline Prunus avium & 8 & 57 & 64.91 & 5.26 & 3.51 & 26.32 & 0.30 \\
\hline Pseudotsuga menziesii & 7 & 19 & 89.47 & 5.26 & 0 & 5.26 & 0.07 \\
\hline Quercus cerris & 8 & 45 & 93.33 & 4.44 & 0 & 2.22 & 0.04 \\
\hline Quercus petraea & 5 & 329 & 82.37 & 9.42 & 2.43 & 5.78 & 0.11 \\
\hline Robinia pseudoacacia & 8 & 29 & 89.66 & 3.45 & 0 & 6.90 & 0.08 \\
\hline Salix spp. & 8 & 26 & 88.46 & 7.69 & 3.85 & 0 & 0.05 \\
\hline Sorbus aria & 8 & 89 & 64.04 & 13.48 & 10.11 & 12.36 & 0.24 \\
\hline Sorbus aucuparia & 8 & 18 & 77.78 & 0 & 0 & 22.22 & 0.22 \\
\hline Sorbus torminalis & 8 & 21 & 85.71 & 4.76 & 0 & 9.52 & 0.11 \\
\hline Tilia spp. & 8 & 19 & 73.68 & 15.79 & 10.53 & 0 & 0.12 \\
\hline Ulmus glabra & 8 & 47 & 46.81 & 21.28 & 17.02 & 14.89 & 0.33 \\
\hline other broadleaves & 8 & 26 & 80.77 & 0 & 3.85 & 15.38 & 0.18 \\
\hline other conifers & 7 & 7 & 85.71 & 0 & 0 & 14.29 & 0.14 \\
\hline all species & & 11,414 & 68.68 & 12.21 & 5.19 & 13.92 & 0.21 \\
\hline
\end{tabular}


Table SM2: The ordinal logistic (OLR) model: the detailed ANOVA table with all included regressors in the

877 model ( $\chi^{2}-$ partial $\chi^{2}$ values, $d f$ - degrees of freedom, $p-p$ value); the predictor was considered as significant if

$878 \mathrm{p}<0.05$; see Table 1 for predictors' abbreviations. For each explanatory variable Higher Order Factors are

879 included in the model in the case of interactions or nonlinear relationship. The significance of interaction terms

880 and nonlinearity for each explanatory variable is tested based on the partial $\chi^{2}$ test.

\begin{tabular}{|c|c|c|c|}
\hline Predictors & $x^{2}$ & $\mathrm{df}$ & $P$ \\
\hline ELV (Factor+Higher Order Factors) & 953.26 & 16 & $<0.01$ \\
\hline all Interactions & 762.98 & 12 & $<0.01$ \\
\hline nonlinear (Factor+Higher Order Factors) & 658.05 & 12 & $<0.01$ \\
\hline SLP (Factor+Higher Order Factors) & 101.54 & 16 & $<0.01$ \\
\hline all Interactions & 49.07 & 12 & $<0.01$ \\
\hline nonlinear (Factor+Higher Order Factors) & 96.39 & 12 & $<0.01$ \\
\hline DINT (Factor+Higher Order Factors) & 1560.68 & 30 & $<0.01$ \\
\hline all Interactions & 866.64 & 27 & $<0.01$ \\
\hline SPEC & 202.42 & 5 & $<0.01$ \\
\hline DBH (Factor+Higher Order Factors) & 47.56 & 4 & $<0.01$ \\
\hline all Interactions & 19.15 & 3 & $<0.01$ \\
\hline SS & 29.14 & 2 & $<0.01$ \\
\hline GINI & 16.08 & 1 & $<0.01$ \\
\hline SWI & 55.86 & 4 & $<0.01$ \\
\hline nonlinear (Factor+Higher Order Factors) & 24.83 & 3 & $<0.01$ \\
\hline DINT * ELV (Factor+Higher Order Factors) & 762.98 & 12 & $<0.01$ \\
\hline nonlinear Interaction : $f(A, B)$ vs. $A B$ & 361.60 & 9 & $<0.01$ \\
\hline DINT * SLP (Factor+Higher Order Factors) & 49.07 & 12 & $<0.01$ \\
\hline nonlinear Interaction : $f(A, B)$ vs. $A B$ & 46.78 & 9 & $<0.01$ \\
\hline DINT * DBH (Factor+Higher Order Factors) & 19.15 & 3 & $<0.01$ \\
\hline TOTAL NONLINEAR & 751.52 & 27 & $<0.01$ \\
\hline TOTAL INTERACTION & 866.64 & 27 & $<0.01$ \\
\hline TOTAL NONLINEAR + INTERACTION & 1078.64 & 36 & $<0.01$ \\
\hline TOTAL & 2420.07 & 51 & $<0.01$ \\
\hline
\end{tabular}

881 
Figure SM1: Schematic presentation of the ice storm intensity modelling procedure. Blue rectangles represent different sets of input measured data. In dark

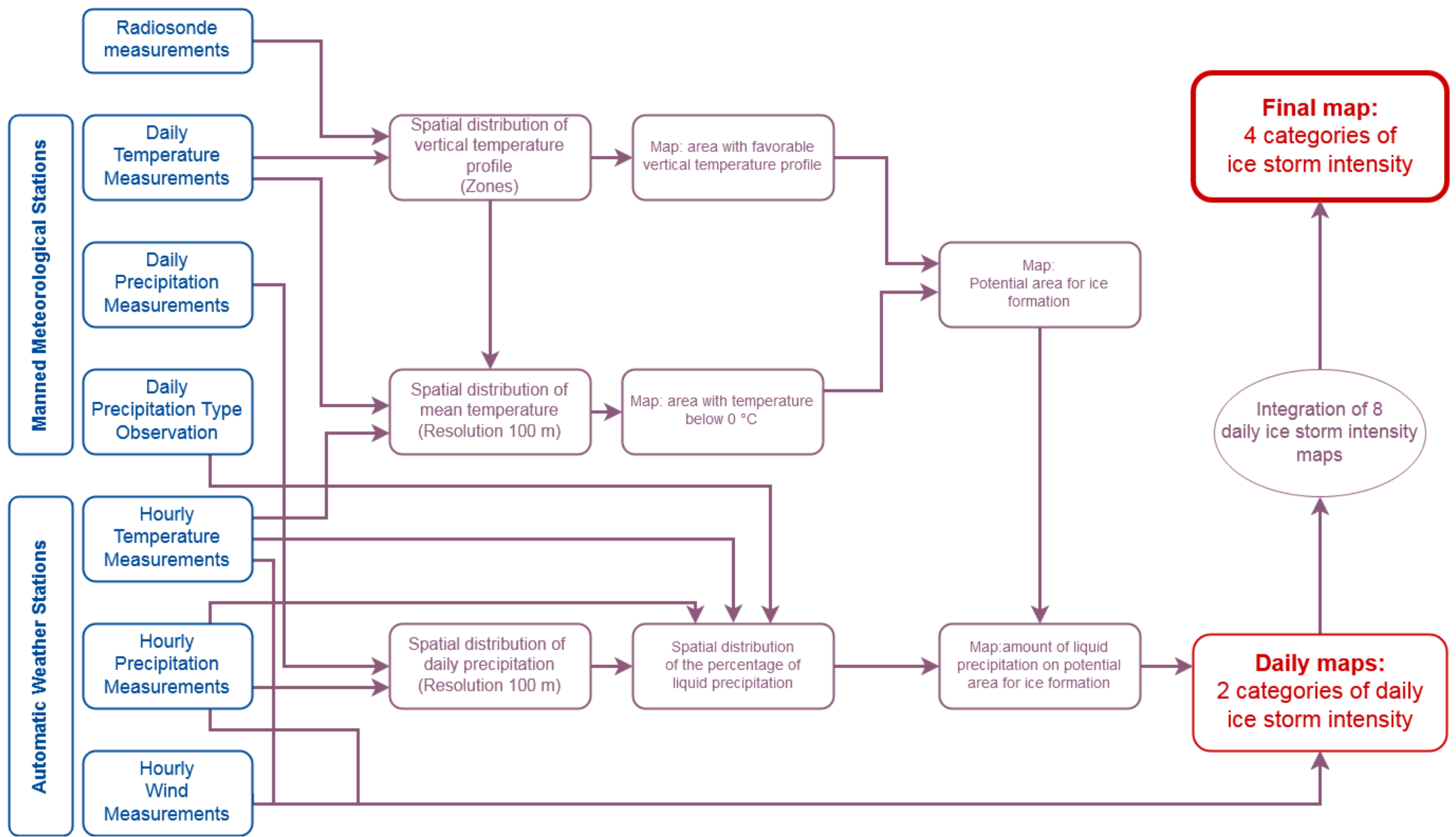


Figure SM2: Predicted probabilities of moderate (D1), severe (D2) and total damage (D3) of tree species in relation to tree size diversity Gini index (GINI) 888 and ice storm intensity (DINT); only trees with social status SS1 (predominant and dominant) were considered; other continuous predictors were held constant at their means

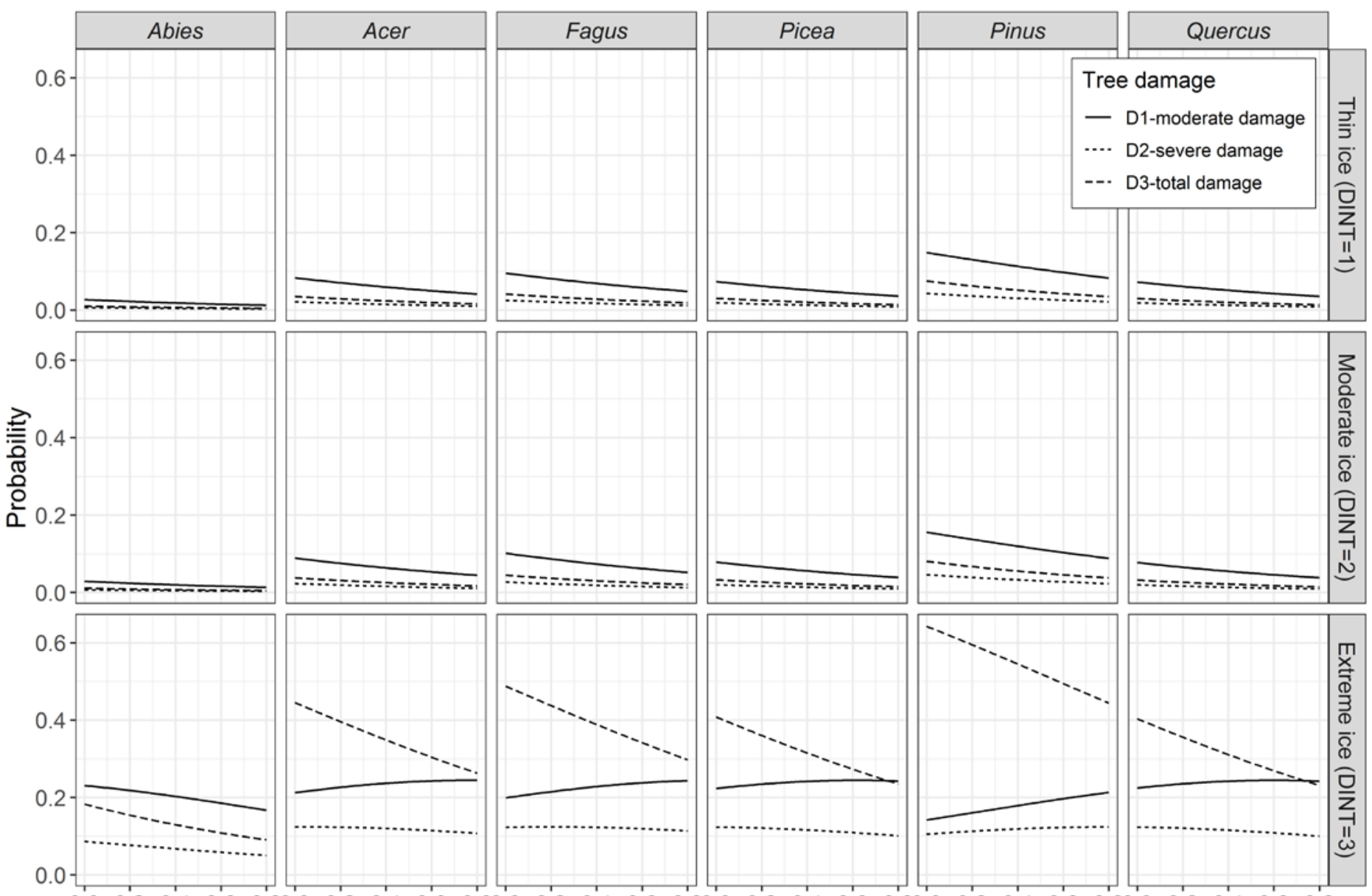


Figure SM3: Predicted probabilities of moderate (D1), severe (D2) and total damage (D3) of tree species in relation to tree species diversity index (SWI) and

892 ice storm intensity (DINT); only trees with social status SS1 (predominant and dominant) were considered; other continuous predictors were held constant 893 at their means

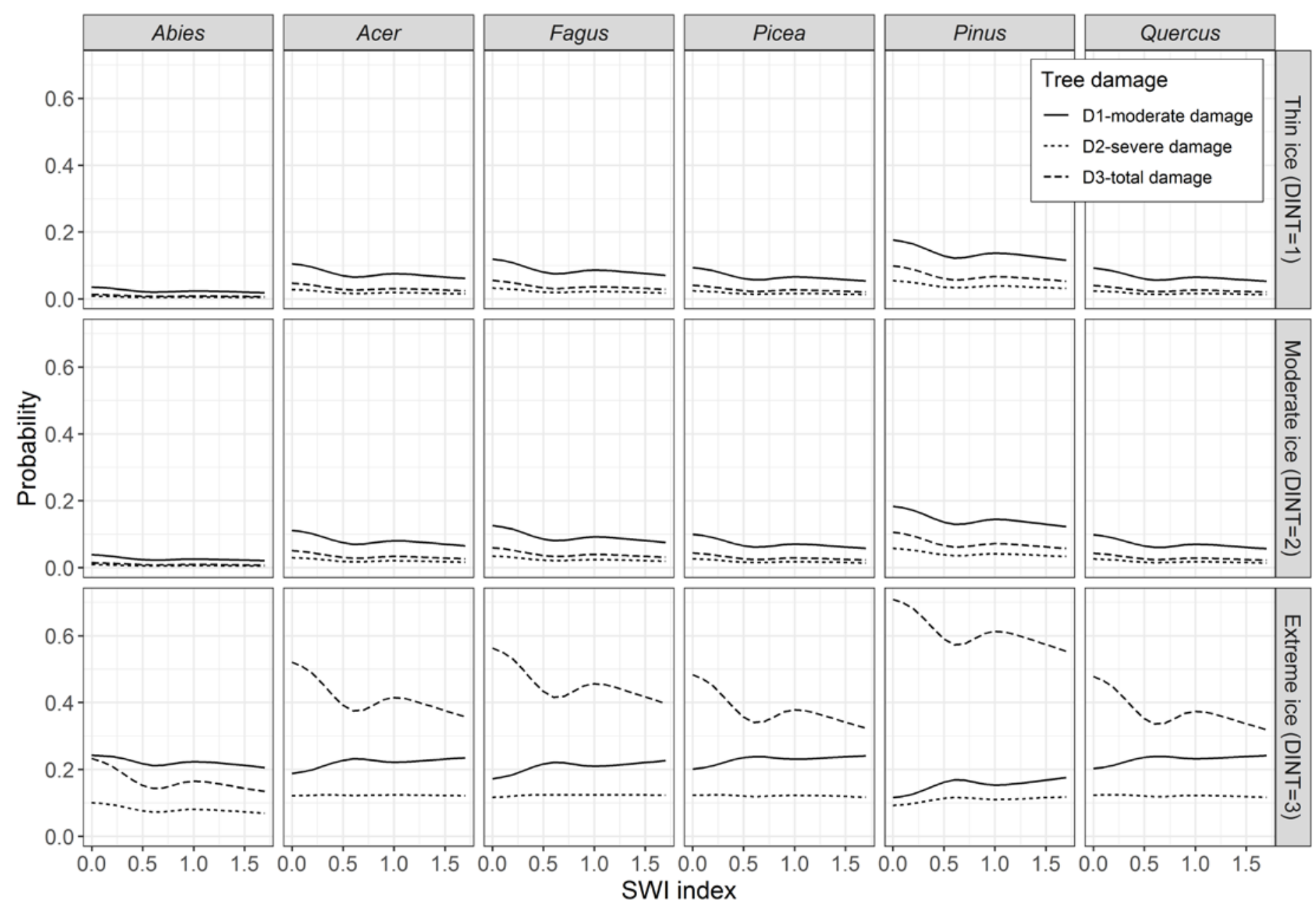


Figure SM4: Predicted probabilities of moderate (D1), severe (D2) and total damage (D3) of tree species for trees with social status SS2 (codominant trees)

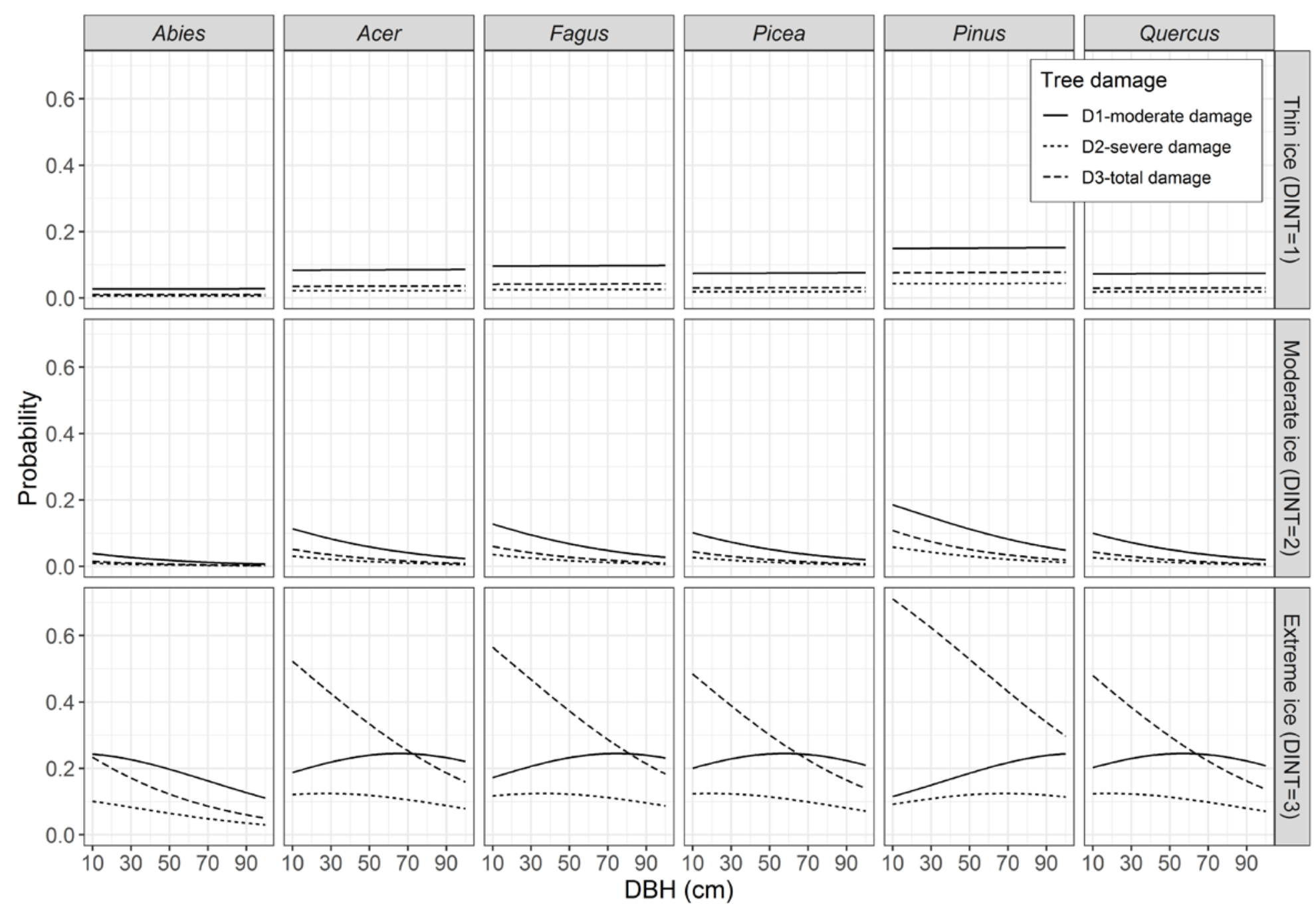


Figure SM5: Predicted probabilities of moderate (D1), severe (D2) and total damage (D3) of tree species for trees with social status SS3 (supressed trees) in

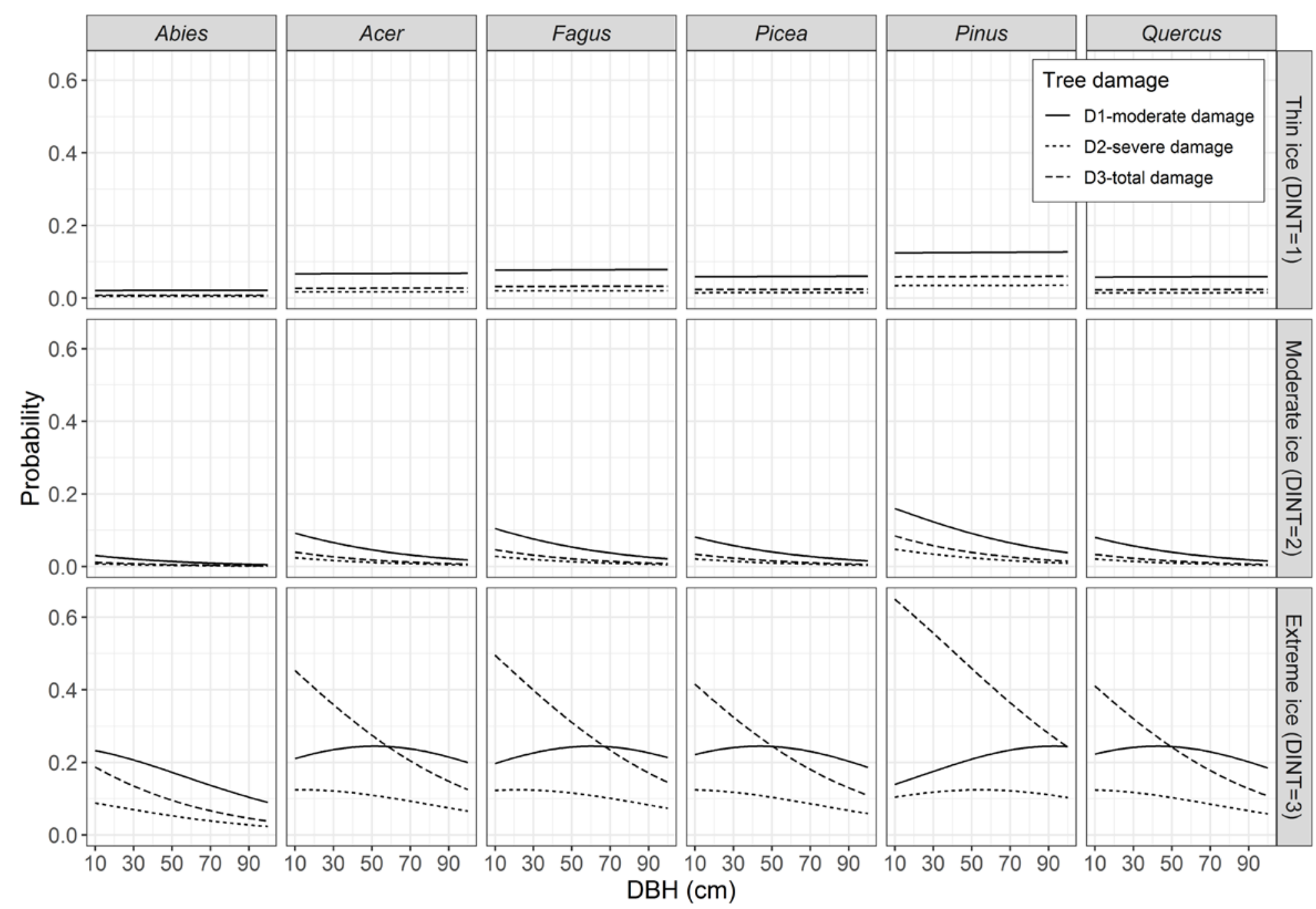


Figure SM6: Predicted probabilities of moderate (D1), severe (D2) and total damage (D3) of tree species in relation to elevation (ELV) and ice storm

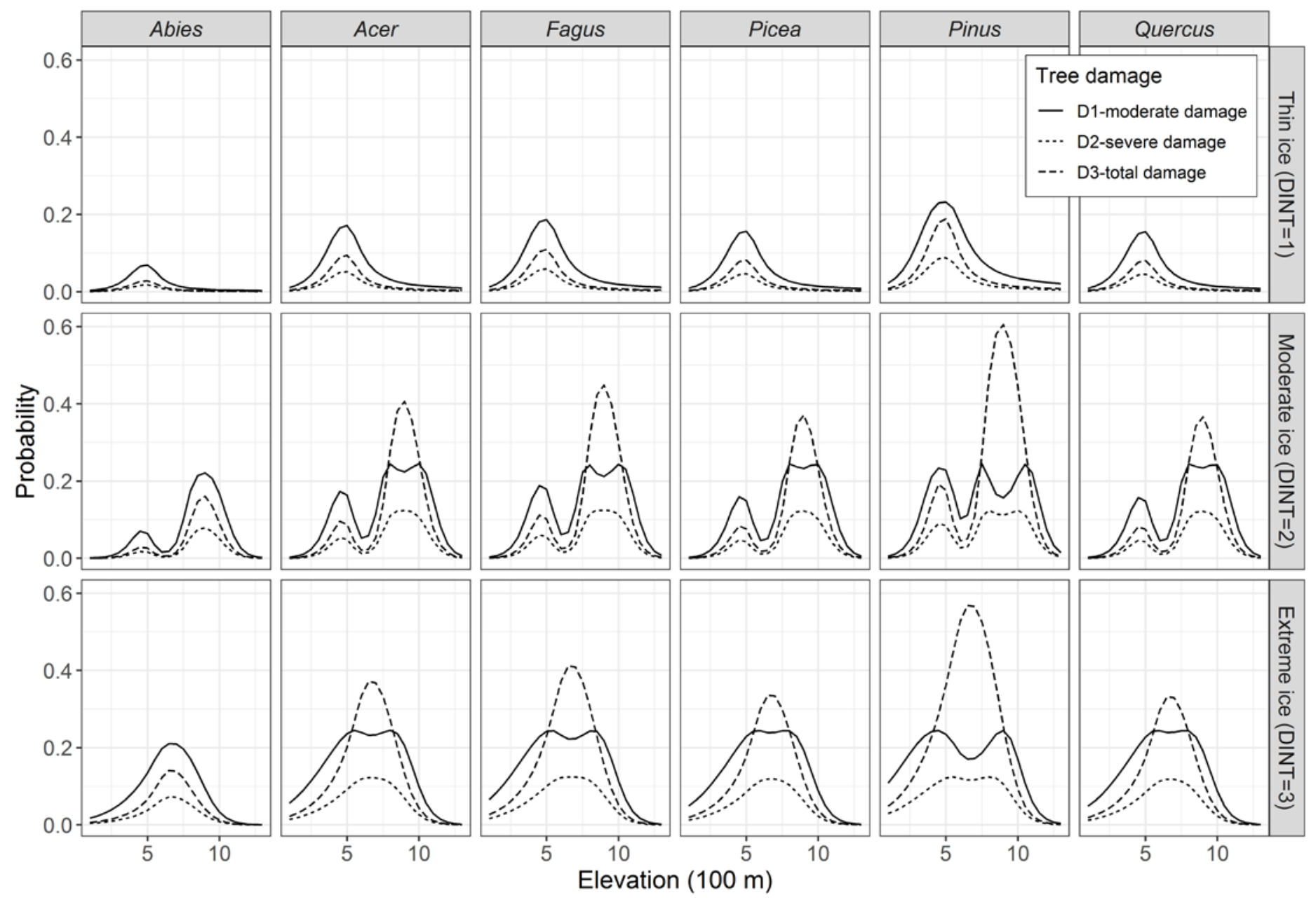


Figure SM7: Predicted probabilities of moderate (D1), severe (D2) and total damage (D3) of tree species in relation to slope (SLP) and ice storm intensity

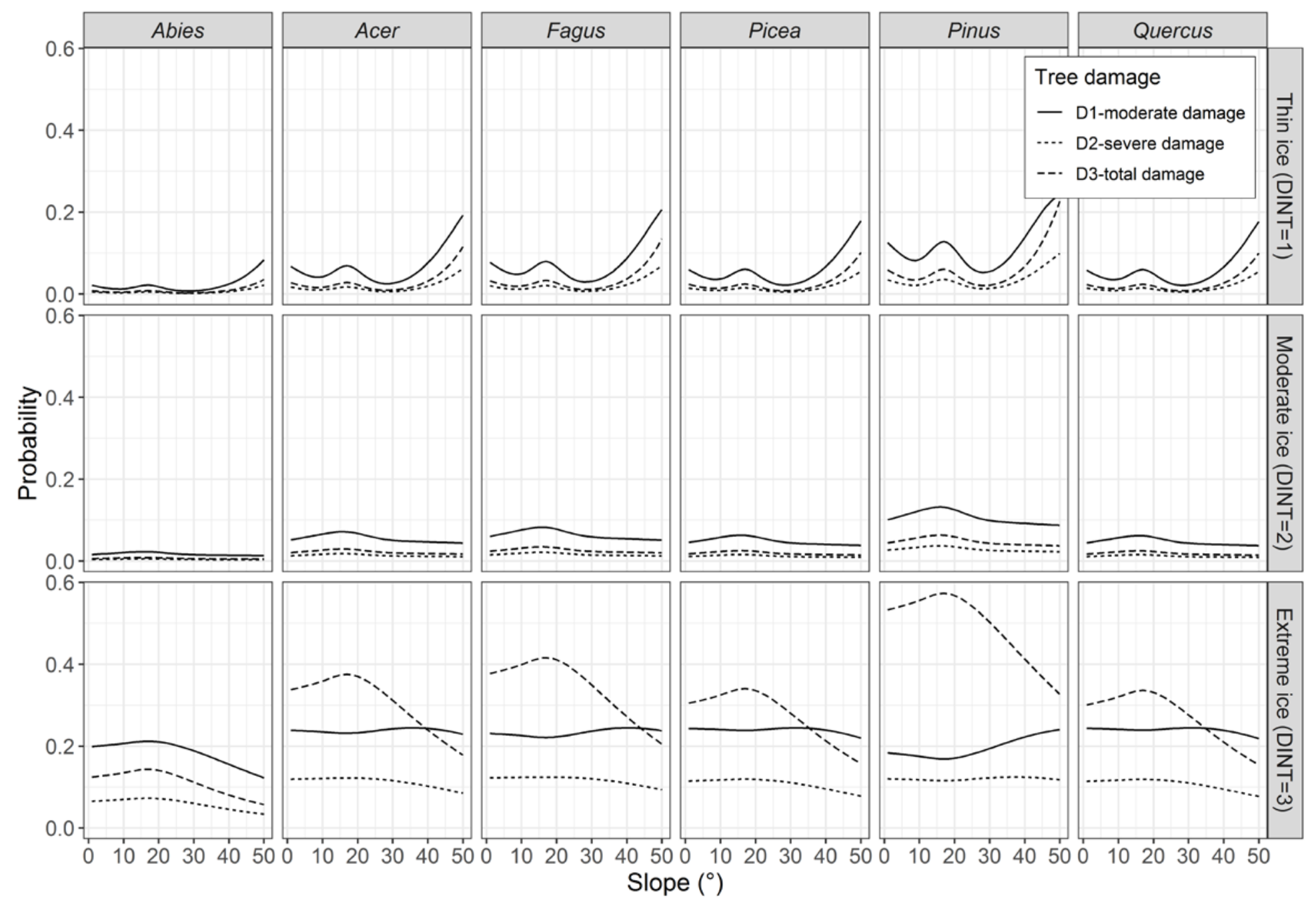

